Accepted refereed manuscript of:

Taylor J, Martinez Rubio L, del Pozo J, Walton J, Tinch AE, Migaud H \& Tocher DR (2015) Influence of dietary phospholipid on early development and performance of Atlantic salmon (Salmo salar), Aquaculture, 448, pp. 262-272.

DOI: $10.1016 / j$. aquaculture.2015.06.012

(C) 2015, Elsevier. Licensed under the Creative Commons AttributionNonCommercial-NoDerivatives 4.0 International http://creativecommons.org/licenses/by-nc-nd/4.0/ 


\section{INFLUENCE OF DIETARY PHOSPHOLIPID ON EARLY DEVELOPMENT AND PERFORMANCE OF ATLANTIC SALMON (Salmo salar)}

John F. Taylor ${ }^{1 *}$, Laura Martinez-Rubio ${ }^{1}$, Jorge del Pozo ${ }^{2}$, James M. Walton ${ }^{3}$, Alan E. Tinch $^{4}$, Herve Migaud ${ }^{1}$, Douglas R. Tocher ${ }^{1}$

${ }^{1}$ Institute of Aquaculture, School of Natural Sciences, University of Stirling, Stirling, FK9 4LA, UK

2 The Royal (Dick) School of Veterinary Studies, Easter Bush Campus, Midlothian, Edinburgh, EH25 9RG, Scotland, UK

${ }^{3}$ BioMar Ltd., North Shore Road, Grangemouth FK3 8UL, UK

${ }^{4}$ Landcatch Natural Selection Ltd., Stirling University Innovation Park, Stirling, FK9 4NF, UK

*Correspondence: E-mail: jft2@stir.ac.uk (J. Taylor)

Tel: 00-44-01786 467929

Fax: 00-44-01768 472133

Keywords: Salmo salar; Phospholipid; Requirement; Phosphatidylcholine; Intestine; Steatosis; Development; Deformity; Nutrition 


\section{Abstract}

The present study aimed to confirm the requirement for dietary phospholipid in Atlantic salmon and better define the level and period of requirement. Thus, the effects of dietary supplementation with phospholipid supplied by krill or soy lecithin were investigated in Atlantic salmon, Salmo salar. First feeding fry were fed diets containing $55 \%$ protein and 17 $\%$ lipid supplemented with krill oil or soybean lecithin in a regression design at five levels, 1.5 (unsupplemented), 2.6, 3.2, 3.6 and $4.2 \%$ total phospholipid and fish were sampled at $1 \mathrm{~g}$ $\left(1400^{\circ}\right.$ day post fertilisation, dpf), $2.5 \mathrm{~g}\left(1990^{\circ} \mathrm{dpf}\right), 5 \mathrm{~g}\left(2350^{\circ} \mathrm{dpf}\right), 10-20 \mathrm{~g}\left(2850^{\circ} \mathrm{dpf}\right)$ and smolt $\left(3800^{\circ} \mathrm{dpf}\right)$. Survival was high overall with a positive correlation $\left(\mathrm{r}^{2}=0.59-0.72\right)$ between survival and dietary phospholipid supplementation. Growth was improved by phospholipid with highest growth achieved in fish fed krill phospholipid at $2.6 \%$ and in fish fed soy lecithin at $3.6 \%$. The pattern of growth differed between fish up to $2.5 \mathrm{~g}$ and that from $2.5 \mathrm{~g}$ onwards with SGR (0-2.5 g) being significantly higher in fish fed $2.6 \%$ krill phospholipid and $3.6 \%$ soy phospholipid compared to the basal diet, whereas there was no difference in SGR $(2.5 \mathrm{~g}$-smolt) between the treatments. Intestinal steatosis was observed in $2.5 \mathrm{~g}$ fish fed the unsupplemented diet (20\% prevalence) and lower levels of soy (10\% prevalence), whereas it was absent from $2.5 \mathrm{~g}$ fish fed krill oil and higher levels of soy lecithin $(\geq 3.2 \%)$, and fish at all later stages. Prevalence of vertebral deformities was low but was reduced by increasing dietary phospholipid with krill oil generally being more effective. The results were consistent with salmon having a dietary requirement for dietary phospholipid in early life stages. 


\section{Introduction}

Since the first report of a dietary phospholipid requirement in an aquatic organism, specifically shrimp (Teshima et al., 1982), it has become well established that inclusion of intact phospholipids in the diet can improve culture performance of various freshwater and marine fish species (Coutteau et al., 1997). The primary criteria used to define the beneficial effects of dietary phospholipid have been growth and survival, but effects on development and stress resistance have also been reported in some species (Coutteau et al., 1997; Cahu et al., 2003b). Phospholipid requirement appears to be restricted to early life stages and so the specific evidence supporting a requirement for dietary intact phospholipid in fish has been improved growth in both larvae and early juveniles, increased survival rates and decreased incidence of malformation in larvae, and perhaps increased stress resistance (Tocher et al., 2008). However, no requirement has been established in adult fish of any species, although this has been largely unstudied (Tocher et al., 2008). In Atlantic salmon (Salmo salar), a requirement for dietary phospholipid based on growth performance was demonstrated in Atlantic salmon of $0.18 \mathrm{~g}, 1.0 \mathrm{~g}$ and $1.7 \mathrm{~g}$ initial weight, whereas in fish of $7.5 \mathrm{~g}$ initial weight, no requirement was observed (Poston, 1990). Dietary supplementation with lecithin also improved survival of $0.18 \mathrm{~g}$ fish but not of larger fish (Poston, 1990).

Most commonly, the levels of phospholipid requirement can vary depending upon species and developmental stage (larvae or juveniles) from around $2 \%$ up to much higher levels of 12 - $14 \%$ of diet (Cahu et al., 2003a; Rinchard et al., 2007). In Atlantic salmon, growth rate was higher in fry of initial weight $0.18 \mathrm{~g}, 1 \mathrm{~g}$ or $1.7 \mathrm{~g}$ fed soy lecithin at $4 \%$ of diet compared to fish fed the basal, unsupplemented feed (Poston, 1990). The phospholipid content of the foodgrade lecithin used was unclear but may have been around $60 \%$, which means the growth enhancement was obtained by supplementing the diet with $2.4 \%$ phospholipid. In a later trial, graded levels of feed-grade lecithin (an approximately 1:1 mix of soy and corn lecithin) were tested in $0.18 \mathrm{~g}$ first-feeding salmon fry and a supplementation level of $6 \%$ provided the 
highest growth rate (Poston, 1991). Again the precise phospholipid content of the lecithin mixture used was not clear but appeared generally similar to food-grade lecithin used previously although it was also reported as being around $90 \%$ as "nutritionally effective" as crude soy lecithin (Poston, 1991). Therefore, supplementation with $6 \%$ feed grade lecithin may represent somewhere between 3.2 and $3.6 \%$ dietary phospholipid.

Based on a few studies where semi-purified phospholipid preparations have been used, the rank order for efficacy generally appears to be phosphatidylcholine (PC) > phosphatidylinositol (PI) > phosphatidylethanolamine $(\mathrm{PE})>$ phosphatidylserine (PS) (Kanazawa, 1983, 1993; Kanazawa et al., 1985), with PC being associated with improved growth performance whereas PI has been associated with increased survival and reduced deformities (Geurden et al., 1998a). The efficacy of other phospholipid classes or sphingolipids is not known (Tocher et al., 2008). In the early studies on Atlantic salmon, the phospholipid class compositions of the lecithin preparations used were not assayed or fully described although it was reported that soybean lecithin was predominantly PC, PE and PI (Poston, 1991) and that the food-grade lecithin used contained around $16 \%$ PC (Poston, 1990). Extrapolating from this figure would suggest that the growth promoting effect of lecithin supplementation was associated with a dietary PC level of around 0.6 to $1.0 \%$.

The mechanism underpinning the role of dietary phospholipids in early life stages of fish is not fully understood. The role appears to not be related to the delivery of other essential dietary components such as essential fatty acids, phosphate or the bases choline and inositol (Tocher et al., 2008). For instance supplemental choline did not replicate the effect of dietary soy lecithin in the early studies on Atlantic salmon (Poston, 1990, 1991). However, studies showed that phospholipid-deficient diets could lead to the accumulation of lipid vacuoles/droplets (steatosis) in enterocytes in fish larvae leading to the suggestion that dietary phospholipids may be required for the efficient export of dietary lipids from the intestine (Fontagné et al., 1998; Geurden et al., 1998b; Olsen et al., 1999; Salhi et al., 1999; Liu et al., 
2002). Furthermore, as phospholipid is required for lipoprotein assembly, it was proposed that the stimulating effects of phospholipids on growth were due to early life stages of fish having limited ability for de novo phospholipid biosynthesis (Geurden et al., 1995, 1999; Fontagné et al., 1998). Thus, dietary phospholipids increase the efficiency of transport of dietary fatty acids and lipids from the gut to the rest of the body possibly through enhanced lipoprotein synthesis (Tocher et al., 2008).

Our overall aim is to determine the precise molecular mechanism(s) underpinning the requirement for dietary intact phospholipid in fish and so one objective of the present study was to provide experimental material for mechanistic studies. Our target species was Atlantic salmon due to the fact that, despite the huge commercial importance of this species, its dietary requirements are generally poorly studied and largely extrapolated from rainbow trout data (NRC, 2011). Dietary phospholipid requirements in Atlantic salmon were last investigated a quarter of a century ago in relatively short-term studies (12-16 weeks), using lecithin preparations with rather undefined phospholipid content and class composition. Therefore, the particular aims of the present study were to confirm the requirement for dietary phospholipid in Atlantic salmon, better define the level of requirement, and further establish the period of requirement. To this end, Atlantic salmon fry were fed diets containing either krill oil or soybean lecithin in a regression design at five levels from first feeding through to parr-smolt transformation. Analyses focused on growth, mortality, vertebral malformation and intestinal histology (steatosis).

\section{Materials and Methods}

To be consistent with previous studies on phospholipid requirements of fish, the term "phospholipid" in the present paper will specifically refer to the glycerophospholipids, the major classes being PC, PE, PS and PI. 


\subsection{Experimental Diets}

Diets were formulated and manufactured by BioMar AS (BioMar Tech Centre, Brande, Denmark). Commercially available feed ingredients were used and diets were formulated to meet the dietary requirements of appropriately sized salmon, including vitamin and mineral requirements (NRC, 2011). Prior to use, the lipid class compositions of the phospholipid products were analysed (see below). The soybean lecithin (Cargill, Germany) was $49 \%$ polar lipids containing $10.4 \%$ PC, $9.2 \%$ PI, $7.5 \%$ PE and $1 \%$ PS, with the remaining polar classes being predominantly glycolipids. The neutral lipids $(51 \%)$ were predominantly triacylglycerol (37\%) with $7 \%$ each of sterols and free fatty acids. The krill oil (Aker Biomarine, Norway) was $40 \%$ polar lipids with $26 \%$ PC and $2 \%$ PE with trace amounts of PI and PS, with the remaining polar lipids being non-glycerophospholipid (e.g. sphingo- and glycolipids) and pigment. The neutral lipids (60 \%) contained $30 \%$ triacylglycerol with $15 \%$ each of sterols and free fatty acids.

A total of nine diets were formulated to deliver target phospholipid levels of basal (unsupplemented) and 4 levels each of krill oil or soybean lecithin. The basal diet mix contained $400 \mathrm{~g} \mathrm{~kg}^{-1}$ of fishmeal (Koster Marine Proteins Gmbh, Germany), $100 \mathrm{~g} \mathrm{~kg}^{-1}$ each of soy protein concentrate (Selecta SPC, Brazil), corn gluten (Cargill, Germany) and wheat gluten (Vest Korn, Norway), $30 \mathrm{~g} \mathrm{~kg}^{-1}$ pea protein (R2 Group, Denmark), $80 \mathrm{~g} \mathrm{~kg}^{-1}$ wheat flour (R2 Group), and $64 \mathrm{~g} \mathrm{~kg}^{-1}$ vitamin/mineral premix (BioMar Premix, Vilomix, Denmark). The added oil component of the diet accounted for $126 \mathrm{~g} \mathrm{~kg}^{-1}$, which was supplied in the basal (unsupplemented) feed by a 3:2 mix of fish oil (Peruvian FO, ED\&F Man, Germany) and rapeseed oil (Emmelev, Denmark). To reach targeted dietary phospholipid levels, krill oil and soybean lecithin were included in the formulations, replacing as much as possible fish oil and rapeseed oil, respectively, as shown in Table 1. The proximate compositions and the lipid class compositions of the nine feeds are shown in Table 2. This shows that the basal, unsupplemented feed still delivered $1.5 \%$ phospholipid, with 4 pairs of feeds delivering on 
average 2.6, 3.2, 3.6 and $4.2 \%$ total phospholipid (sum of PC, PE, PI and PS). The feed design aimed to balance dietary fatty acid compositions as much as possible but this was not fully successful at the highest inclusion of phospholipid (Table 3). The feeds were all produced by extrusion and were fed from first feeding through to smolt with appropriately increasing pellet sizes from $0.5 \mathrm{~mm}$. The data presented in Tables 1-3 show mean values for the $0.5,0.8$ and $1.1 \mathrm{~mm}$ feeds that covered the fish from first feeding to $5 \mathrm{~g}$.

\subsection{Experimental fish}

The feeding trial was carried out at the University of Stirling freshwater facilities (Niall Bromage Freshwater Research Facility, Stirling, UK) with all experimental procedures conducted in compliance with the Animals Scientific Procedures Act 1986 (UK Home Office Code of Practice. HMSO: London January 1997) in accordance with EU regulation (EC Directive 86/609/EEC) and approved by the Animal Ethics and Welfare Committee of the University of Stirling. The stock used was produced from two sea-winter broodstock fish with a full five-generation pedigree available from the Landcatch breeding programme (Landcatch Natural Selection Ltd, Stirling University Innovation Park, UK). Eyed Atlantic salmon ova (380 ays) were supplied in January 2012 and randomly distributed (2000 ova / tank) between 9 square $1 \times 1 \mathrm{~m}$ fibreglass hatching tanks $\left(0.3 \mathrm{~m}^{3}, 10.6 \mathrm{~L} \mathrm{~min}^{-1}, \mathrm{O}_{2}>8 \mathrm{mg} \mathrm{L}^{-1}\right)$ on flow-through supplied by spring water at ambient temperature $\left(6.6 \pm 0.7{ }^{\circ} \mathrm{C}\right)$ and maintained in complete darkness under blackout covers until first feeding. At first-feeding $\left(900^{\circ}\right.$ day post fertilisation, 19 March 2012), fry were maintained under constant light (LL) and water temperature increased to $9.5 \pm 1.0{ }^{\circ} \mathrm{C}$ and fed one of 9 experimental diets (one tank per diet) according to the manufacturer's tables by clockwork belt feeders over a $24 \mathrm{~h}$ period. Tanks were flushed once daily, and mortalities recorded twice daily. In mid-May 2012, fry $(\sim 0.75$ g) were transferred to smolt rearing tanks with each dietary treatment now fed to duplicate circular covered fibreglass tanks, each of $2 \mathrm{~m}$ diameter $\left(1.6 \mathrm{~m}^{3}, 15 \mathrm{~L} \mathrm{~min}^{-1}, \mathrm{O}_{2}>8 \mathrm{mg} \mathrm{L}^{-1}\right)$, on 
ambient water temperature, range $1.0^{\circ} \mathrm{C}$ (winter) $-15.5^{\circ} \mathrm{C}$ (summer). Fish were maintained on LL until September 2012 where the photoperiod was changed to simulated natural photoperiod (SNP) until completion of smoltification in April 2013, with illumination provided by two $28 \mathrm{~W}$ fluorescent daylight bulbs ( $4000^{\circ} \mathrm{K}$, RS Components, UK) positioned centrally in the tank lids $0.4 \mathrm{~m}$ above the surface. Fish in all tanks were fed continuously during the light period by automatic feeders (Arvotec T Drum 3L; Arvotec, Finland) controlled by a computer-aided (PC) system. Specific feeding rates (SFR; \% tank biomass per day) were adjusted automatically according to predicted growth and daily temperature. Fish were fed experimental feeds with pellet size increasing from $0.5 \mathrm{~mm}$ at start of feeding to 2.0 $\mathrm{mm}$ at smoltification.

\subsection{Sampling Procedures}

Environmental parameters and mortality were recorded twice per day for the duration of the trial. Fish were sampled for growth at approximately $1 \mathrm{~g}\left(1400^{\circ}\right.$ day post fertilisation, dpf), $2.5 \mathrm{~g}\left(1990^{\circ} \mathrm{dpf}\right), 5 \mathrm{~g}\left(2350^{\circ} \mathrm{dpf}\right), 10-20 \mathrm{~g}\left(2850^{\circ} \mathrm{dpf}\right)$ and smolt $\left(3800^{\circ} \mathrm{dpf}\right)$. At each time point 50 fish / tank were anaesthetised (MS222, PHARMAQ, UK), individual weights ( \pm $0.1 \mathrm{~g})$ and fork lengths $( \pm 1.0 \mathrm{~mm})$ measured, and fish allowed to recover in aerated water before returning to experimental tanks. In addition, a total of 5 fish / tank $(n=10 /$ diet) were euthanized by an overdose of MS222, livers and intestine dissected out and stored in $10 \%$ neutral buffered formalin or SERRA fixative (ethanol / formalin / acetic acid, 6:3:1 by vol.) respectively, for histological analyses (Dapra et al., 2011). A further 30 fish per dietary group were euthanized in an overdose of MS222 at termination of the trial and frozen flat on trays at $-20^{\circ} \mathrm{C}$ for later x-ray analysis of spinal deformity.

\subsection{Feed analyses}


Feeds were ground prior to determination of proximate composition according to standard procedures (AOAC, 2000). Moisture contents were obtained after drying in an oven at $110{ }^{\circ} \mathrm{C}$ for $24 \mathrm{~h}$ and ash content determined after incineration at $600{ }^{\circ} \mathrm{C}$ for $16 \mathrm{~h}$. Crude protein content was measured by determining nitrogen content $(\mathrm{N} \times 6.25)$ using automated Kjeldahl analysis (Tecator Kjeltec Auto 1030 analyzer, Foss, Warrington, U.K), and crude lipid content determined after acid hydrolysis followed by Soxhlet lipid extraction (Tecator Soxtec system 2050 Auto Extraction apparatus, Foss, Warrington, U.K). Total lipid was extracted by chloroform/methanol $(2: 1, \mathrm{v} / \mathrm{v})$ and content determined gravimetrically (Folch et al., 1957). Lipid class composition of dietary lipid was determined by high performance thinlayer chromatography (HPTLC) using $10 \times 10 \mathrm{~cm}$ HPTLC plates (VWR, Lutterworth, England) and classes quantified by scanning densitometry using a CAMAG-3 TLC scanner (version Firmware 1.14.16) (Henderson and Tocher, 1992). Scanned images were recorded automatically and analysed using winCATS Planar Chromatography Manager, version 1.2.0). Fatty acid methyl esters (FAME) were prepared from total lipid by acid-catalysed transesterification at $50{ }^{\circ} \mathrm{C}$ for $16 \mathrm{~h}$ (Christie, 2003), and FAME extracted and purified as described previously (Tocher and Harvie, 1988). FAME were separated and quantified by gas-liquid chromatography using a Fisons GC-8160 (Thermo Scientific, Milan, Italy) equipped with a $30 \mathrm{~m} \times 0.32 \mathrm{~mm}$ i.d. $\times 0.25 \mu \mathrm{m}$ ZB-wax column (Phenomenex, Cheshire, UK), on-column injector and a flame ionisation detector. Data were collected and processed using Chromcard for Windows (version 2.01; Thermoquest Italia S.p.A., Milan, Italy). Individual FAME were identified by comparison to known standards and published data (Tocher and Harvie, 1988).

\subsection{Saltwater Challenge}

Groups of 10 randomly selected fish from the largest and smallest (by weight) krill or soy lecithin dietary groups were subjected to a saltwater challenge at approximately 300 
$\left(3635^{\circ} \mathrm{dpf}\right), 400\left(3718^{\circ} \mathrm{dpf}\right), 500\left(3872^{\circ} \mathrm{dpf}\right)$ and $550^{\circ}$ days post-winter solstice. The test was conducted for $24 \mathrm{~h}$ in $100 \mathrm{~L}$ tanks of $10^{\circ} \mathrm{C}$ aerated seawater $(35 \mathrm{ppt}$ ) (Instant Ocean; Animal House, Batley, UK). Each diet was stocked into a separate 100 L tank. Following challenge, all fish were removed, numbers of surviving fish counted to determine seawater survival, and were then culled and blood removed from the caudal vein before centrifugation at $500 \mathrm{~g}$ for 15 min at $4{ }^{\circ} \mathrm{C}$. Serum was collected and stored at $-20{ }^{\circ} \mathrm{C}$ until analysis of serum chloride using a chloride analyser (Sherwood Instruments Inc., UK). Serum samples were analysed in triplicate per individual and the average taken of the three technical replicates.

\subsection{Histological Analysis}

Serra fluid fixed intestines $(\mathrm{n}=10$ / treatment, 5 fish/tank $)$ from fry at $2.5 \mathrm{~g}\left(1990^{\circ} \mathrm{dpf}\right)$ and parr at $10-20 \mathrm{~g}\left(2850^{\circ} \mathrm{dpf}\right)$ were measured for enterocyte height, and presence/absence of steatosis from the mid-intestine after paraffin wax embedding. Longitudinal sections $(4 \mu \mathrm{m}$ thick) were stained with Alcian blue, periodic acid Schiff reagent and Mayer's haematoxylin $(\mathrm{AB} / \mathrm{PAS})$. For each fish, the height of five apical enterocytes were measured in a randomly chosen mid-intestinal fold by image analysis (Abramoff et al., 2004). Enterocyte heights were considered as the linear distance between the basal surface and the luminal edge of the brush border (passing through the enterocyte nucleus). Additionally, all fish were measured for the presence of enterocyte steatosis in the first part of the mid-intestine (i.e. immediately aboral to the last pyloric caecum). The term steatosis was applied when clear vacuoles with a diameter greater than $5 \mu \mathrm{m}$ were observed in the enterocytes, and measurement was achieved using a three-point scoring system $(0=$ no hepatocyte vacuolization observed; $1=$ mild hepatic vacuolization; and 2 = severe hepatocyte vacuolization).

\subsection{Spinal Deformity - X Ray Radiography}


Frozen fish ( $\mathrm{n}=30$ / treatment, 15 fish / tank) were $\mathrm{x}$-radiographed using a portable $\mathrm{x}$ ray unit (Celtic SMR PX40 HF) with an extremities plate measuring $24 \mathrm{~cm}$ x $30 \mathrm{~cm}$. Each radiograph was exposed for $32 \mathrm{mAs}$ and $40 \mathrm{kV}$ and the image digitized (AGFA CR-35X). The radiographs were observed using Adobe Photoshop CS 6 (version 13.0.1, Adobe system Incorporated, California, USA) with the spine divided into four sections, regions 1, 2, 3, and 4 (Kacem et al., 1998) and deformity type categorised according to Witten et al. (2006). Observations were made in the anterior-caudal direction. The total number of vertebra was recorded for each fish.

\subsection{Statistical analysis}

All data are means \pm S.D unless otherwise specified. Percentage data were subjected to arcsine square-root transformation prior to statistical analyses. Data were tested for normality and homogeneity of variances with Levene's test prior to one-way analysis of variance followed by a Tukey-Kramer HSD multiple comparisons of means. Contingency chi-square tests were used to compare significant differences between deformed and non-deformed vertebrae. All statistical analyses were performed using Minitab software (v16.1, Pennsylvania, USA).

\section{Results}

\subsection{Growth and survival}

A significant correlation $\left(r^{2}=0.59-0.72\right)$ between increasing dietary phospholipid supplementation and decreased mortality was observed with both dietary phospholipid sources (Fig. 1). At smolt, overall mortality was $17 \%$ lower in fish fed diets supplemented with krill oil than those supplemented with soybean lecithin (average mortality, $4.02 \pm 0.51$ vs. $4.72 \pm 0.60 \%$, respectively), with both being significantly lower than fish fed the basal unsupplemented diet $(5.42 \pm 0.49 \%)$ (Table 4$)$. It should be noted that the group fed the 
highest level of krill phospholipid were terminated on ethical grounds after the 10-20 $\mathrm{g}$ sample as examination of unexpected mortalities had shown some fish were showing a cestode infection and so all fish were culled on veterinary advice. Testing at the time and at termination of the trial revealed no other treatments were infected.

From first-feeding $\left(900^{\circ} \mathrm{dpf}\right)$ to $\sim 1 \mathrm{~g}\left(1400^{\circ} \mathrm{dpf}\right)$ weight increased with increasing phospholipid supplementation in both dietary phospholipid sources (Fig. 2A). Fish fed the krill phospholipid supplemented diets showed significantly higher mean weights than fish fed the respective soy lecithin supplemented diets, and this aspect was maintained throughout development although by smolt the only significant difference observed in final weight within respective phospholipid supplementation levels was at $2.6 \%$ (Fig. 2E). All dietary groups, with the exception of the lowest level of soy lecithin supplementation (2.6\% phospholipid), achieved a significantly greater weight than fish fed the basal unsupplemented diet at $1 \mathrm{~g}$. As development progressed ( $>1990^{\circ} \mathrm{dpf}, \geq 2.5 \mathrm{~g}$, Figs. 2B-D) weight gain started to decrease in fish fed higher levels of dietary phospholipid. In fish fed the krill oil, the highest weight gain was consistently observed in fish fed $2.6 \%$ phospholipid and higher inclusions showing a decreasing trend in weight, that became increasingly significant with development and inclusion level (Figs. 2B-D). In fish fed the soy lecithin, weight increased with increased inclusion levels up to $3.6 \%$ phospholipid but then decreased in fish fed $4.2 \%$ phospholipid (Figs. 2B-E). The pattern of fish weight observed at $\sim 2.5 \mathrm{~g}$ (Fig. 2B), with the highest weights being attained in fish fed $2.6 \%$ krill phospholipid and $3.6 \%$ soy phospholipid, was maintained through development (Figs. 2C-E). This pattern was reflected in the higher overall SGR and TGC, and lower apparent FCR in fish fed these treatments when calculated at smolt (Table 3).

Therefore, there was a clear difference in the pattern of growth observed between fish fed the two PL preparations with fish fed krill oil showing better growth performance than those fed soy lecithin. However, irrespective of PL source, there was also a difference in the effects 
of dietary PL on growth early in early development (measured at $\sim 1 \mathrm{~g}$ ) and that observed from $2.5 \mathrm{~g}$ onwards. This was highlighted by comparing SGR in the different developmental periods with SGR (0-2.5 g) showing significantly better growth performance in fish fed $2.6 \%$ krill phospholipid and $3.6 \%$ soy phospholipid compared to fish fed the basal diet, whereas there was no difference in SGR or TGC between these treatments when measured from $2.5 \mathrm{~g}$ to smolt (Fig. 3).

\subsection{Intestinal histology and steatosis}

At $2.5 \mathrm{~g}$, mid-intestine enterocyte height did not differ significantly between any dietary treatment or phospholipid source $(44.4 \pm 1.5 \mu \mathrm{m}, p=0.492)$. However, intestinal steatosis was clearly observed in fish fed both the basal unsupplemented and the $2.6 \%$ soy phospholipid diets with a prevalence of $20 \%$ and $10 \%$ of fish affected, respectively. Steatosis was characterized by several clear, variably sized, intracytoplasmic vacuoles in mostly apical enterocytes of the mid intestine (Fig. 4). No steatosis was observed in the intestine of $2.5 \mathrm{~g}$ fish fed any of the krill phospholipid-supplemented diets or in fish fed $3.2 \%$ or higher levels of soy phospholipid. In addition, no steatosis was observed in the intestines of fish fed any of the dietary treatments at 10-20 g.

\subsection{Skeletal development and spinal deformity}

The overall prevalence of radiological detectable spinal deformity was generally low in smolt fed all treatment groups, varying between 4 and $16 \%$ (Fig. 5A). Highest prevalence was observed in fish fed the basal unsupplemented diet. There was no significant difference between any supplemented dietary group other than the $3.6 \%$ krill phospholipid which had a significantly lower prevalence of deformity. However, there was a general trend of decreasing deformity with increasing krill phospholipid supplementation. In the soy phospholipid groups vertebral deformity was significantly reduced at $3.2 \% \mathrm{PL}$ and above compared to the 
unsupplemented or $2.3 \%$ soy PL diets. The mean number of deformed vertebra (dV) per deformed fish did not differ significantly between any dietary group other than the $3.6 \%$ krill phospholipid group, which had a significantly lower number of dV than fish fed the basal and $2.6 \%$ krill phospholipid diets (Fig. 5B).

The predominant location of vertebral deformities was in the most cranial and caudal parts of the vertebral column in all dietary groups (Fig. 5C). The vertebrae most affected in these regions were $\mathrm{v} 3$ in $\mathrm{R} 1$ and $\mathrm{v} 55$ in $\mathrm{R} 4$ in fish fed either phospholipid source. There was also a higher (double) prevalence in these regions in fish fed soy phospholipid than fish fed krill phospholipid. Three predominant pathology types were observed, these being: decrease of intervertebral space (Type 1); compression (Types 2-5); and loss of symmetry due to dorsal or ventral shifting of the vertebra centre (Type 19). These three pathologies accounted for 32.2, 42.4 and $23.7 \%$, respectively, of all deformity in fish fed the basal unsupplemented diet. The same pattern, with Types 2-5 predominating, was observed in fish fed krill phospholipid diets with the proportions being $27.9,49.0$ and $22.3 \%$. In contrast, in fish fed soy phospholipid the pathologies were more even distributed at 33.6, 32.4 and $31.5 \%$.

\subsection{Smoltification and seawater adaptation}

Saltwater challenge survival was $100 \%$ in fish fed $2.6 \%$ krill phospholipid from 300 ${ }^{\circ} \mathrm{d}\left(3635^{\circ} \mathrm{dpf}\right)$ to $550^{\circ} \mathrm{d}$ post winter solstice (Fig. 6). In contrast, fish fed $3.6 \%$ krill phospholipid, and 2.6 and $3.6 \%$ soy phospholipid showed significantly lower seawater challenge survival at $300{ }^{\circ} \mathrm{d}$ post winter solstice. Subsequent seawater challenges showed an improvement in survival in these three groups concomitant with increased body weight. At $500{ }^{\circ} \mathrm{d}$ post winter solstice and beyond, all dietary groups returned a seawater challenge survival of $100 \%$ (Fig. 6). Plasma chloride levels decreased with time in all dietary groups $\left(191.5 \pm 8.5\right.$ to $\left.158.5 \pm 9.2 \mathrm{mmol} \mathrm{L}^{-1}\right)$, but did not differ significantly between krill and soy phospholipid supplemented groups (data not shown). 


\section{Discussion}

Although it is well-known that the inclusion of intact phospholipids in the diet can improve growth, survival and development in early life stages of various freshwater and marine fish species (Coutteau et al., 1997), the only reports on phospholipid requirements in Atlantic salmon were a quarter of a century ago (Poston, 1990, 1991). Therefore, the specific aims of the present study were to investigate the requirement for dietary phospholipid in Atlantic salmon and better define the level and time of requirement and, if possible, the relative importance of individual phospholipid classes. In addition to effects on growth and survival, the present study provided novel data on the effects of dietary phospholipid on intestinal steatosis, skeletal development and seawater adaptation in Atlantic salmon.

Before discussing in detail the relevant results of the present study it is necessary to be clear about what these were and how they relate, or not, to the aims of the study.

1. Initially, at first feeding, fish fed krill oil had a significantly better growth rate than fish fed soy lecithin. Specifically, fish fed krill oil attained higher weights than fish fed soy lecithin at the equivalent phospholipid inclusion levels, and so this effect was not linked to dietary phospholipid content. Furthermore, as weight of fish at equivalent PC levels was also higher in fish fed krill oil, it was not related to the PC content.

2. However, irrespective of whether from krill oil or soy lecithin, supplemental phospholipid to first feeding fry up to $2850^{\circ} \mathrm{dpf}$ increased growth/weight over fry fed the basal diet and so there was an effect of dietary phospholipid.

3. In fish fed krill oil, the highest weight was obtained in fish fed $2.6 \%$ total phospholipid, whereas within fish fed soy lecithin a higher level total phospholipid was required $(3.6 \%)$ to give highest weight among the soy-fed fish. This difference between krill and soy lecithin, distinct to the overall difference noted in point 1 , may be linked to the level of individual 
phospholipid classes such as PC in the different phospholipid ingredients, and this was partially supported by the effects on intestinal steatosis and skeletal deformities.

Therefore, point 1 above was an ingredient/raw material effect not related to the focus of the study, dietary phospholipid, and it complicated interpretation of the data. In particular it prevented further interpretation of the data in terms of individual phospholipid classes because, although the two phospholipid preparations were rather different in phospholipid class composition, the confounding raw material effect prevented identification of effects unequivocally due to phospholipid class. Precisely what was responsible is not known but krill meals are well-known have attractant/appetite stimulating properties. As waste feed was not able to be recovered at first feeding, fish were fed to excess and therefore it is likely the higher growth was due to increased feed intake in the krill oil fish.

Based on growth performance and survival data, Poston $(1990,1991)$ concluded that Atlantic salmon of initial weight up to $1.7 \mathrm{~g}$ showed a requirement for dietary phospholipid whereas fish of $7.5 \mathrm{~g}$ initial weight showed no requirement. In the present study, the numerical weights of fish at $1990^{\circ} \mathrm{dpf}$ (approximately $1 \mathrm{~g}$ ) increased in a graded manner with increasing phospholipid supplementation in fish fed both dietary phospholipid sources. In addition, survival at smolt was improved in fish fed supplementary dietary phospholipid. Further analyses of growth performance, specifically SGR, in the present study showed that the growth promoting effect of dietary phospholipid was observed in the period from first feeding to $2.5 \mathrm{~g}\left(2850^{\circ} \mathrm{dpf}\right)$ and not from $2.5 \mathrm{~g}$ to smolt, indicating that the requirement for dietary phospholipid was restricted to early fry. Therefore, these basic data confirmed that Atlantic salmon have a requirement for dietary phospholipid in early development up to around $2850^{\circ} \mathrm{dpf}$ although the precise time could be slightly earlier or later. In the previous studies on salmon, the dietary requirement for phospholipid appeared to decrease with development as the requirement was reportedly $6 \%$ in $0.18 \mathrm{~g}$ fish (Poston, 1991), around $4 \%$ in fish of $1.7 \mathrm{~g}$, and not present in $7.5 \mathrm{~g}$ fish (Poston, 1990). 
The phospholipid level to satisfy dietary requirements in fish has been difficult to unequivocally establish due to the use of a wide range of phospholipid sources that can vary considerably both in phospholipid content and class composition (Tocher et al., 2008). As the present study was a long-term trial from first feeding to smolt using several inclusion levels, the use of purified phospholipids was not possible. However, in contrast to many studies, both the phospholipid sources (krill oil and soy lecithin) and the feeds were fully analysed so that the precise content and compositions were known. Therefore, we can be clear that the highest growth rate in early development was obtained with fish fed phospholipid at $2.6 \%$ of diet when krill oil was supplemented and that final smolt weights were highest, and not different, between fish fed $2.6 \%$ krill and $3.6 \%$ soy phospholipid. These dietary percentages represent the sum of the four main glycerophospholipids, PC, PE, PS and PI.

In comparison, in the early studies of Poston $(1990,1991)$, growth rate in salmon up to 1.7 g was higher in fish fed diets supplemented with $4-6 \%$ lecithin compared to fish fed an unsupplemented diet. It should be noted that these data are actually reporting the levels of the lecithin products that were supplemented to the feeds, and not the actual phospholipid or glycerophospholipid levels. Indeed, different lecithins were used and their precise compositions were not reported, but some estimates of actual phospholipid and glycerophospholipid levels can be extrapolated from the data given in Poston (1990, 1991). Thus, the lecithins were both approximately $60 \%$ polar lipid and so the total phospholipid/polar lipid in diets containing 4 - $6 \%$ lecithin would have been around $2.4-3.6$ $\%$, respectively. Furthermore, in the present study, total glycerophospholipid (PC+PE+PI+PS) accounted for around $70 \%$ of the total polar lipids in the soybean lecithin used and, assuming similar proportions in the soy and soy/corn lecithins used in Poston $(1990,1991)$, dietary inclusion levels of 4 and $6 \%$ lecithin would actually equate to around $1.7-2.5 \%$ (glycero)phospholipids. This is in the same range as found in the present study and so we can be confident that the dietary requirement for phospholipid in Atlantic salmon is at the lower 
end of the spectrum of levels reported for fish species (Coutteau et al., 1997; Cahu et al., 2003a,b; Tocher et al., 2008).

A further interesting result in the present study was that growth decreased in fish fed krill phospholipid at levels higher than $2.6 \%$ at later times in development, and also decreased in fish fed the highest soy (above the 'optimum' of $3.6 \%$ of diet). This was unexpected and largely unprecedented and so not fully understood. One hypothesis is that this is due to the fact that dietary phospholipids do not provide as much energy as triacylglycerols and this becomes important in later life stages (Bell and Koppe, 2011). Therefore, in the early life stages when there is a limitation in enterocyte metabolism, the role of intact dietary phospholipid, and especially PC, in promoting lipoprotein biosynthesis (Cole et al., 2012) and, consequently, export of dietary lipid from the intestine (Field and Mathur, 1995) is predominant and is manifested in improved growth. However, in later life stages, when there is no impairment of metabolism in enterocytes and dietary intact phospholipid has no or reduced role in promoting export of dietary lipid from the intestine (Mansbach, 2000), the relative energy contents of phospholipid and triacylglycerol become more important. Therefore, the more dietary lipid as phospholipid rather than triacylglycerol will tend to lower growth due to reduced energy content and so, at high phospholipid levels, well above any "requirement" level, dietary phospholipid can result in reduced growth.

The new data obtained on intestinal steatosis in the present study provided support for several ideas and hypotheses advanced for phospholipid requirements in fish. Firstly, the fact that intestinal steatosis was only observed in $2.5 \mathrm{~g}$ fish and not in any later developmental stages supports the conclusion that salmon only have a requirement for dietary intact phospholipid in the early fry stage. Secondly, however, it may also suggest an association with PC based on the fact that steatosis was only observed in $2.5 \mathrm{~g}$ fish in those being fed the diets with the lowest level of PC, namely the basal diet (0.8 \% PC) and the lowest level of soy supplementation (1.3\% PC). All feeds with PC above this level (i.e. from 1.5 to $3.3 \%$ PC) 
showed no intestinal steatosis. These data support previous studies that showed intestinal steatosis induced in carp larvae fed phospholipid-deficient diets was prevented by dietary PC and, to a lesser extent, PI (Fontagné et al., 1998). Finally, the observation of steatosis in salmon enterocytes supported the hypothesis that dietary phospholipid was required for the efficient export of dietary lipid from the intestine. Previous studies showed that diets deficient in phospholipid could lead to lipid accumulation in intestinal enterocytes in fish larvae (Fontagné et al., 1998; Olsen et al., 1999; Salhi et al., 1999; Liu et al., 2002). Based on these studies it was suggested that dietary phospholipid was required for the efficient exportation of dietary lipid from enterocytes (Fontagné et al., 1998; Geurden et al., 1998a; Olsen et al., 1999; Salhi et al., 1999). The mechanism was proposed to be associated with lipoprotein assembly, specifically the outer phospholipid "coat" and so the stimulating effects of phospholipids were due to early life stages of fish having limited ability to biosynthesise phospholipids de novo (Geurden et al., 1995, 1999; Coutteau et al., 1997; Fontagné et al., 1998).

The precise mechanism of how dietary phospholipid and, specifically, PC affect intestinal lipoprotein synthesis is not entirely clear. In the intestinal cell line, CaCo-2, supplementary PC increased the secretion of triacylglycerol-rich lipoproteins (Mathur et al., 1996). It may be simply that PC is required for lipoprotein assembly as the phospholipid 'coat' of chylomicrons is predominantly PC, with only small amounts of sphingomyelin and PE (Field and Mathur, 1995). However, PC also affects the synthesis and secretion of the main apolipoproteins of chylomicrons, apolipoproteins B and A-I. Thus, PC increased the rate of apoB secretion whereas PE, PS and sphingomyelin did not (Field et al., 1994), and intestinal apoA-I synthesis was shown to be regulated by dietary PC in newborn swine (Wang et al., 2001). Furthermore, in liver cells, phospholipid synthesis has been linked to the secretion of apoB-containing lipoproteins (Yao and Vance, 1989) and PC increased the secretion of newly-synthesized triacylglycerols (Field and Mathur, 1995). Therefore, there may be 
biochemical mechanisms linking dietary phospholipid and, especially, PC, to lipoprotein synthesis and secretion.

Vertebral deformities at smolt assessed by x-ray radiography in this study showed a relatively low prevalence (4 - 16\%) in fish fed all diets, and are towards the lower end of those reported in Atlantic salmon (6.0 - $73.3 \%$, Fjelldal et al., 2007, 2009; Witten et al., 2009). Deformities were predominantly located in the cranial trunk (R1) and tail fin (R4), consistent with other reports in S1+ unvaccinated smolts (Fraser et al., 2014). Furthermore, the pathology type, principally compressions, did not differ between dietary pospholipid source. However, although prevalence was low, there was a general decrease in spinal deformity with increasing dietary phospholipid in both krill and soy groups relative to fish fed the non-supplemented diet. Studies on the effects of dietary phospholipid on skeletal development in salmonids are somewhat limited compared to other fish species (Cahu et al., 2003b). In rainbow trout, no beneficial effect of dietary phospholipid supplementation on malformations at any developmental stage $(0.2$ or $0.5 \mathrm{~g})$ was reported, although it was noted there was a higher degree of ossification in fish fed phospholipid-supplemented diets than in fish fed phospholipid-free diets (Daprà et al., 2011). By contrast, in marine larvae and other freshwater species, it has been widely shown that increased dietary phospholipid reduced spinal malformation (Cahu et al., 2003b), and that PI in particular was predominantly associated with reduced deformities (Geurden et al., 1998b; Cahu et al., 2003a). The mechanism by which PI regulates skeletal development is not fully understood, but it may regulate calcium entry into the cell (Cahu et al., 2003a), which may be stimulating osteocalcin (BGP) production to promote bone mineralisation (Sandel et al., 2010).

However, the present data on salmon are not entirely consistent with those reported previously for the beneficial role of PI. In the case of fish fed the soy phospholipid diets, spinal deformity was highest in the base diet ( $\sim 0.24 \%$ PI, PC:PI ratio 3.4$)$, reduced in fish fed the $2.6 \%$ soy supplemented group ( $0.53 \%$ PI, PC:PI of 2.5$)$, and was lowest in the $3.2-4.2$ 
\% soy phospholipid diets (0.80 - $0.99 \%$ PI, PC:PI of 1.8) and, therefore, was consistent with the malformation reducing effect of increasing dietary PI. In contrast, fish fed the krill PL diets where spinal deformity decreased with increasing krill oil inclusion, PI remained more or less constant at $0.21-0.26 \%$, whereas PC levels increased (1.3 to $3.3 \%$ ) and, therefore, the PC:PI ratio (8.4 to 13.1) also increased. Thus, PI level per se would not appear to be responsible for the reduction in deformity in the krill-supplemented diet. However, Coutteau et al. (1997) noted that the interactive importance of both PC and PI is not well understood, and suggested that relative importance of phospholipid classes could be species specific. Recently in both Atlantic cod (Gadus morhua) and gilthead seabream (Sparus aurata), it was indicated that both dietary PI levels and PC:PI ratio are important in reducing deformity levels in larvae and early juveniles while supporting optimal growth (Sandel et al., 2010; Hansen et al., 2011). In the case of sea bream a decreasing PC:PI ratio promoted growth, while lowered dietary PI increased jaw malformation yet, conversely, increasing PI (i.e. reduced PC:PI ratio) showed a trend towards increased spinal malformation, particularly in faster growing individuals. In the present study on salmon, the lowest krill supplemented group, $2.6 \%$ phospholipid, was the fastest growing group but with the highest deformity level, yet corresponded to the lowest PC:PI ratio (8.4) and is thus consistent with the observations in sea bream. In contrast, soy phospholipid supplemented diets showed the opposite effect where deformity decreased with decreasing PC:PI ratio supporting the direct role of PI as the main dietary phospholipid contributing to the reduction in malformation. Sandel et al. (2010) propose that while high PI diets correlated well with high growth rate and reduced jaw deformity, the apparent upregulation of osteocalcin production may lead to overmineralisation of the skeleton. Collectively these findings suggest that there needs to be an effective PC:PI ratio to promote growth but minimise specific deformity within each species and, in light of the present study, may also be dependent on origin of the dietary phospholipid source. 
In conclusion, the present study confirmed that Atlantic salmon have a dietary requirement for intact phospholipid in early development. Fish fed the low phospholipid (unsupplemented) diet showed lowest growth and survival, highest level of spinal deformities and displayed intestinal steatosis. Supplementary phospholipid increased growth, improved survival, reduced spinal deformities and prevented steatosis. The data on growth and steatosis indicated that the requirement for dietary phospholipid was restricted to fish of up to 2850 ${ }^{\circ} \mathrm{dpf}(\sim 2.5 \mathrm{~g})$. In addition to providing new data characterising the phospholipid requirement of Atlantic salmon, a major aim of the present trial was to provide intestinal and liver samples for gene expression analyses. These ongoing studies aim to elucidate the molecular mechanism(s) of dietary phospholipid requirement and to define the genes/enzymes or pathways that may be deficient in early life stages, potentially limiting phospholipid/PC production in enterocytes that, as a consequence, constrains chylomicron production and export of dietary lipid from the intestine.

\section{Acknowledgements}

This study, JFT and LMR were partly funded by the European Commission FP7 Integrated Project No. 288925, Advanced Research Initiatives for Nutrition \& Aquaculture (ARRAINA).

\section{References}

Abramoff, M.D., Magalhaes, P.J., Ram, S.J., 2004. Image processing with ImageJ. Biophotonics Internat., 11, 36-42.

AOAC, 2000. Official Methods of Analysis. Association of Official Analytical Chemists, Gaithersburg, Maryland, USA. 
Bell, J.G., Koppe, W., 2011. Lipids in aquafeeds. In: Turchini, G.M., Ng, W.-K., Tocher, D.R. (Eds). Fish Oil Replacement and Alternative Lipid Sources in Aquaculture Feeds. Taylor \& Francis, CRC Press, Boca Raton, pp. 21-59..

Cahu, C., Zambonino Infante, J., Barbosa, V., 2003a. Effect of dietary phospholipid level and phospholipid:neutral lipid value on the development of sea bass (Dicentrarchus labrax) larvae fed a compound diet. Br. J. Nutr. 90, 21-28.

Cahu, C., Zambonino Infante, J., Takeuchi, T., 2003b. Nutritional components affecting skeletal development in fish larvae. Aquaculture 227, 245-258.

Christie, W.W., 2003. Preparation of derivates of fatty acids. In: Christie, W.W. (Ed.). Lipid Analysis: Isolation, Separation and Structural Analysis of Lipids. 3rd ed. Oily Press Ltd., Dundee, pp. 205-225.

Cole, L.K., Vance, J.E., Vance, D.E., 2012. Phosphatidylcholine biosynthesis and lipoprotein metabolism. Biochim. Biophys. Acta 1821, 754-761.

Coutteau, P., Geurden, I., Camara, M.R., Bergot, P., Sorgeloos, P., 1997. Review on the dietary effects of phospholipids in fish and crustacean larviculture. Aquaculture 155, 149164.

Daprà, F., Geurden, I., Corraze, G., Bazin, D., Zambonino-Infante, J.-L., Fontagné-Dicharry, S., 2011. Physiological and molecular responses to dietary phospholipids vary between fry and early juvenile stages of rainbow trout (Oncorhynchus mykiss). Aquaculture 319, 377 384.

Field, F.J., Mathur, S.N., 1995. Intestinal lipoprotein synthesis and secretion. Prog. Lipid Res. $34,185-198$.

Field, F.J., Born, E., Chen, H., Murthy, S., Mathur, S.N., 1994. Regulation of apolipoprotein B secretion by biliary lipids in CaCo-2 cells. J. Lipid Res. 35, 749-762. 
Fjelldal, G., Hansen, T.J., Berg, A.E., 2007. A radiological study on the development of vertebral deformities in cultured Atlantic salmon (Salmo salar L.). Aquaculture 273, 721 728.

Fjelldal, P.G., Glover, K.A., Skaala, O., Imsland, A., Hansen, T.J., 2009. Vertebral body mineralization and deformities in cultured Atlantic salmon (Salmo salar L.): effects of genetics and off-season smolt production. Aquaculture 296, 36-44.

Fontagné, S., Geurden, I., Escaffre, A.-M., Bergot, P., 1998. Histological changes induced by dietary phospholipids in intestine and liver of common carp (Cyprinus carpio L.) larvae. Aquaculture 161, 213-223.

Fraser, T.W.K., Hansen, T., Mayer, I., Skjæraasen, J.E., Glover, K.A., Sambraus, F., Fjelldal, P.G., 2014. The effect of triploidy on vaccine side-effects in Atlantic salmon. Aquaculture 433, 481-490.

Geurden, I., Radünz-Neto, J., Bergot, P., 1995. Essentiality of dietary phospholipids for carp (Cyprinus carpio L.) larvae. Aquaculture 131, 303-314.

Geurden, I., Bergot, P., Schwarz, L., Sorgeloos, P., 1998b. Relationship between dietary phospholipids class composition and neutral lipid absorption in post-larval turbot. Fish Physiol. Biochem. 19, 217-228.

Geurden, I., Marion, D., Charlon, N., Coutteau, P., Bergot, P., 1998a. Comparison of different soybean phospholipidic fractions as dietary supplements for common carp, Cyprinus carpio, larvae. Aquaculture 161, 225-235.

Geurden, I., Bergot, P., Van Ryckeghem, K., Sorgeloos, P., 1999. Phospholipid composition of common carp (Cyprinus carpio) larvae starved or fed different phospholipid classes. Aquaculture 171, 93-107.

Hansen, Ø., Puvanendran, V., Jøstensen, J.P., Ous, C., 2011. Effects of dietary levels and ratio of phosphatidylcholine and phosphatidylinositol on the growth, survival and deformity of Atlantic cod larvae and early juveniles. Aquacult. Res. 42, 1026-1033. 
Henderson, R.J., Tocher, D.R., 1992. Thin-layer chromatography. In: Hamilton, R.J., Hamilton, S., (Eds.), Lipid Analysis: A Practical Approach. Oxford University Press, Oxford, pp. 65-111.

Kacem, A., Meunier, F.J., Baglinière, J.L., 1998. A quantitative study of morphological and histological changes in the skeleton of Salmo salar during its anadromous migration. J. Fish Biol. 53, 1096-1109.

Kanazawa, A., 1983. Effect of phospholipids on aquatic animals. Feed Oil Abst. 18, 1-5.

Kanazawa, A., 1993. Essential phospholipids of fish and crustaceans. In: Kaushik, S.J., Luquet, P. (Eds.), Fish Nutrition in Practice. IV International Symposium on Fish Nutrition and Feeding, INRA, France, National Institute for Agricultural Research, Paris, pp. 519530.

Kanazawa, A., Teshima, S., Sakamoto, M., 1985. Effects of dietary bonito-egg phospholipids and some phospholipids on growth and survival of the larval ayu, Plecoglossus altivelis. Z. Angew. Ichthyologie 4, 165-170.

Liu, J., Caballero, M.J., Izquierdo, M.S., El-Sayed Ali, T., Hernández-Cruz, C.M., Valencia, A., Fernández-Palacios, H., 2002. Necessity of dietary lecithin and eicosapentaenoic acid for growth, survival, stress resistance and lipoprotein formation in gilthead sea bream Sparus aurata. Fisheries Sci. 68, 1165-1172.

Mansbach, C.M., 2000. Triacylglycerol movement in enterocytes. In: Mansbach, C.M., Tso, P., Kuksis, A. (Eds.). Intestinal Lipid Metabolism. Kluwer Academic/Plenum Publishers, New York, pp. 215-229.

Mathur, S.N., Born, E., Murthy, S., Field, F.J., 1996. Phosphatidylcholine increases the secretion of triacylglycerol-rich lipoproteins by CaCo-2 cells. Biochem. J. 314, 569-575.

NRC, 2011. Nutrient requirements of fish and shrimp, National Academies Press. National Research Council (NRC), Washington D.C. 
Olsen, R.E., Myklebust, R., Kaino, T., Ringø, E., 1999. Lipid digestibility and ultrastructural changes in the enterocytes of Arctic char (Salvelinus alpinus L.) fed linseed oil and soybean lecithin. Fish Physiol. Biochem. 21, 35-44.

Poston, H.A., 1990. Effect of body size on growth, survival and chemical composition of Atlantic salmon fed soy lecithin and choline. Prog. Fish Cult. 52, 226-230.

Poston, H.A., 1991. Response of Atlantic salmon fry to feed-grade lecithin and choline. Prog. Fish Cult. 53, 224-228.

Rinchard, J., Czesny, S. and Dabrowski, K., 2007. Influence of lipid class and fatty acid deficiency on survival, growth, and fatty acid composition in rainbow trout juveniles. Aquaculture 264, 363-371.

Salhi, M., Izquierdo, M.S., Hernandez-Cruz, C.M., Bessonart, M., Fernandez-Palacios, H., 1999. Effect of different dietary polar lipid levels and different n-3 HUFA content in polar lipid on the gut and liver histological structure of seabream (Sparus aurata) larvae. Aquaculture 179, 253-264.

Sandel, E., Nixon, O., Lutzky, S., Ginsbourg, B., Tandler, A., Uni, Z., Koven, W., 2010. The effect of dietary phosphatidylcholine/phosphatidylinositol ratio on malformation in larvae and juvenile gilthead seabream (Sparus aurata). Aquaculture 304, 42-48.

Teshima, S.I., Kanazawa, A., Sasada, H., Kawasaki, M., 1982. Requirements of the larval prawn, Penaeus japonicus, for cholesterol and soybean phospholipids. Mem. Fac. Fish. Kagoshima Univ, 31, 193-199.

Tocher, D.R., Harvie, D.G., 1988. Fatty acid compositions of the major phosphoglycerides from fish neural tissues; (n-3) and (n-6) polyunsaturated fatty acids in rainbow trout (Salmo gairdneri) and cod (Gadus morhua) brains and retinas. Fish Physiol. Biochem. 5, 229-239.

Tocher, D.R., Bendiksen, E.Å., Campbell, P.J., Bell, J.G., 2008. The role of phospholipids in nutrition and metabolism of teleost fish. Aquaculture 280, 21-34. 
Wang, H., Du, J., Lub, S., Yaob, Y., Hunter, F., Black, D.D., 2001. Regulation of intestinal apolipoprotein A-I synthesis by dietary phosphatidylcholine in newborn swine. Lipids 36, 683-687.

Witten, P.E., Gil-Martens, L., Huysseune, A., Takle, H., Hjelde, K., 2009. Towards a classification and an understanding of developmental relationships of vertebral body malformations in Atlantic salmon (Salmo salar L.). Aquaculture 295, 6-14.

Yao, Z., Vance, D. E., 1989. Head group specificity in the requirement of phosphatidylcholine biosynthesis for very low density lipoprotein secretion from cultured hepatocytes. J. Biol. Chem. 264, 11373-11380. 


\section{Figure Legends}

Fig. 1. Correlation between dietary phospholipid content (percentage of diet) and cumulative mortality from first feeding until smolt (percentage). The basal unsupplemented diet is represented by the black square and fish fed krill or soy phospholipids are represented by the closed and open circles.

Fig. 2. Weight (g) of salmon fry and parr fed increasing dietary phospholipid (percentage of diet) at selected points during development. Fish were sampled at approximately $1 \mathrm{~g}$ (A, 1400 ${ }^{\circ}$ day post fertilisation), $2.5 \mathrm{~g}\left(\mathrm{~B}, 1990^{\circ} \mathrm{dpf}\right), 5 \mathrm{~g}\left(\mathrm{C}, 2350^{\circ} \mathrm{dpf}\right), 10-20 \mathrm{~g}\left(\mathrm{D}, 2850{ }^{\circ} \mathrm{dpf}\right)$ and smolt $\left(\mathrm{E}, 3800^{\circ} \mathrm{dpf}\right)$. Data are means $\pm \mathrm{SD}(\mathrm{n}=2$, i.e. per tank, 50 fish/tank). Different superscript letters indicate significant differences $(\mathrm{p}<0.05)$ between treatments within each growth/developmental phase.

Fig. 3. Effect of development and dietary phospholipid on specific growth rate (SGR) of salmon. SGR $\mathrm{wt}_{\mathrm{wt}}\left(\% \mathrm{day}^{-1}\right)$ was determined in fry over the period from first feeding to $2.5 \mathrm{~g}$, and in parr from $2.5 \mathrm{~g}$ to smolt. Different superscript letters indicate significant differences ( $\mathrm{p}$ $<0.05)$ within each growth/developmental phase. Data are means $\pm \operatorname{SD}(n=2$, i.e. per tank, 50 fish/tank). Different superscript letters indicate significant differences $(p<0.05)$ between treatments within each growth/developmental phase.

Fig. 4. Steatosis in intestine. Longitudinal paraffin embedded sections of mid-intestine (Alcian blue PAS staining, 40x), showing A) normal intestine of fish fed $2.6 \%$ krill phospholipid, and B) intestine of fish fed the basal unsupplemented diet presenting enterocyte steatosis. Arrow is indicating several clear, variably sized, intracytoplasmic vacuoles in mostly apical enterocytes. 
Fig. 5. Skeletal deformities determined in smolt. A) Prevalence of radiological deformed vertebra in Atlantic salmon smolts fed either krill oil or soy lecithin supplemented diets, B) Mean number deformed vertebrae per deformed fish, and C) Percentage localisation of deformed vertebrae along the vertebral column (v1-59). Superscripts denote significant differences between dietary groups. Data are means \pm SEM $(n=2$, i.e. per tank, 15 fish per tank). Different superscript letters indicate significant differences $(p<0.05)$ between treatments.

Fig. 6. Effect of dietary phospholipid on smoltification as determined by change in survival following seawater challenge (35 ppt for $24 \mathrm{hr}$ ). The broken line indicates point where smoltification would be expected to be complete (i.e. $\sim 400^{\circ}$ day post winter solstice under ambient photoperiod). 
Table 1. Inclusion levels $(\mathrm{g} / \mathrm{Kg}$ ) of oil components in the nine experimental feeds

\begin{tabular}{|c|c|c|c|c|c|c|c|c|c|}
\hline & \multicolumn{9}{|c|}{ Target phospholipid level (percentage of diet) } \\
\hline & \multirow[t]{2}{*}{ Base } & \multicolumn{2}{|c|}{2.5} & \multicolumn{2}{|c|}{3.0} & \multicolumn{2}{|l|}{3.5} & \multicolumn{2}{|l|}{4.0} \\
\hline & & Krill & Soy & Krill & Soy & Krill & Soy & Krill & Soy \\
\hline Krill oil & 0 & 26 & 0 & 50 & 0 & 76 & 0 & 126 & 0 \\
\hline Soybean lecithin & 0 & 0 & 24 & 0 & 49 & 0 & 73 & 0 & 122 \\
\hline Fish oil STD 18 & 75 & 50 & 75 & 25 & 75 & 0 & 53 & 0 & 4 \\
\hline Rapeseed oil & 51 & 50 & 26 & 51 & 1 & 50 & 0 & 0 & 0 \\
\hline
\end{tabular}


Table 2. Proximate compositions (percentage of wet weight) and lipid class compositions (percentage of total lipid) of experimental feeds

\begin{tabular}{|c|c|c|c|c|c|c|c|c|c|}
\hline & \multirow{2}{*}{$\begin{array}{l}1.5 \% \mathrm{PL} \\
\text { Base }\end{array}$} & \multicolumn{2}{|l|}{$2.6 \% \mathrm{PL}$} & \multicolumn{2}{|l|}{$3.2 \% \mathrm{PL}$} & \multicolumn{2}{|l|}{$3.6 \% \mathrm{PL}$} & \multicolumn{2}{|l|}{$4.2 \% \mathrm{PL}$} \\
\hline & & Krill & Soy & Krill & Soy & Krill & Soy & Krill & Soy \\
\hline \multicolumn{10}{|c|}{ Proximate composition } \\
\hline Protein & $54.8 \pm 0.4$ & $55.2 \pm 0.1$ & $55.1 \pm 0.4$ & $55.4 \pm 0.0$ & $55.1 \pm 0.1$ & $55.5 \pm 0.1$ & $55.3 \pm 0.3$ & $56.4 \pm 0.2$ & $55.4 \pm 0.3$ \\
\hline Lipid & $17.0 \pm 0.6$ & $17.8 \pm 0.3$ & $17.2 \pm 0.8$ & $17.6 \pm 0.6$ & $17.3 \pm 1.0$ & $17.3 \pm 0.9$ & $17.0 \pm 0.2$ & $16.8 \pm 0.5$ & $16.7 \pm 0.7$ \\
\hline Ash & $8.4 \pm 0.1$ & $8.5 \pm 0.1$ & $8.4 \pm 0.0$ & $8.5 \pm 0.1$ & $8.6 \pm 0.1$ & $8.7 \pm 0.1$ & $8.8 \pm 0.1$ & $8.9 \pm 0.1$ & $9.1 \pm 0.1$ \\
\hline Moisture & $5.6 \pm 0.1$ & $5.5 \pm 0.1$ & $5.9 \pm 0.1$ & $5.4 \pm 0.1$ & $6.1 \pm 0.1$ & $5.2 \pm 0.2$ & $5.9 \pm 0.1$ & $5.5 \pm 0.2$ & $5.4 \pm 0.2$ \\
\hline \multicolumn{10}{|c|}{ Lipid class composition } \\
\hline $\mathrm{PC}$ & $4.8 \pm 0.6$ & $10.1 \pm 0.5$ & $7.3 \pm 0.2$ & $12.9 \pm 1.3$ & $8.4 \pm 0.4$ & $16.3 \pm 0.8$ & $9.1 \pm 0.5$ & $19.6 \pm 1.0$ & $10.8 \pm 1.3$ \\
\hline PE & $2.7 \pm 0.2$ & $2.8 \pm 0.1$ & $4.4 \pm 0.1$ & $3.0 \pm 0.2$ & $5.9 \pm 0.3$ & $3.3 \pm 0.3$ & $6.1 \pm 0.4$ & $3.5 \pm 0.4$ & $7.3 \pm 1.2$ \\
\hline PI & $1.4 \pm 0.1$ & $1.2 \pm 0.2$ & $3.1 \pm 0.6$ & $1.3 \pm 0.1$ & $4.7 \pm 0.2$ & $1.5 \pm 0.2$ & $5.0 \pm 0.1$ & $1.5 \pm 0.0$ & $5.9 \pm 1.5$ \\
\hline PS & $0.1 \pm 0.1$ & $0.3 \pm 0.1$ & $0.4 \pm 0.1$ & $0.3 \pm 0.2$ & $0.5 \pm 0.1$ & $0.5 \pm 0.1$ & $0.6 \pm 0.1$ & $0.6 \pm 0.4$ & $0.7 \pm 0.1$ \\
\hline Total $\mathrm{PL}^{1}$ & $9.0 \pm 0.4$ & $14.4 \pm 0.4$ & $15.2 \pm 0.4$ & $17.5 \pm 0.8$ & $19.5 \pm 0.5$ & $21.6 \pm 0.6$ & $20.8 \pm 0.5$ & $25.2 \pm 0.8$ & $24.7 \pm 1.3$ \\
\hline PL $(\% \text { diet })^{2}$ & 1.5 & 2.6 & 2.6 & 3.1 & 3.3 & 3.7 & 3.5 & 4.2 & 4.1 \\
\hline Tot. Polar ${ }^{3}$ & $18.4 \pm 0.8$ & $23.7 \pm 0.6$ & $27.7 \pm 0.9$ & $28.2 \pm 0.5$ & $34.6 \pm 0.6$ & $31.8 \pm 0.2$ & $37.8 \pm 2.1$ & $38.5 \pm 0.8$ & $47.1 \pm 2.7$ \\
\hline Tot. Neutral ${ }^{4}$ & $81.6 \pm 0.8$ & $76.3 \pm 0.6$ & $72.3 \pm 0.9$ & $71.8 \pm 0.5$ & $65.4 \pm 0.6$ & $68.2 \pm 0.2$ & $62.2 \pm 2.1$ & $61.5 \pm 0.8$ & $52.9 \pm 2.7$ \\
\hline
\end{tabular}

Values are the averaged data for the $0.5,0.8$ and $1.1 \mathrm{~mm}$ feeds (with SD provided simply to illustrate variance between feeds)

PC, phosphatidylcholine; PE, phosphatidylethanolamine; PI, phosphatidylinoslitol; PL, phospholipid; PS, phosphatidylserine; Tot., Total.

${ }^{1}$ Total of the glycerophospholipid classes (PC + PE + PI +PS) as percentage of total lipid; ${ }^{2}$ Total PL expressed as a percentage of diet; ${ }^{3}$ Total polar lipids including glycolipids, pigment material; ${ }^{4}$ Total neutral lipids, predominantly triacylglycerol but including sterols, free fatty acids and steryl esters. 
Table 3. Fatty acid compositions (Percentage of total fatty acids) of experimental feeds supplemented with krill oil or soybean lecithin.

\begin{tabular}{|c|c|c|c|c|c|c|c|c|c|}
\hline & \multirow{2}{*}{$\begin{array}{l}1.5 \% \mathrm{PL} \\
\text { Base }\end{array}$} & \multicolumn{2}{|l|}{$2.6 \% \mathrm{PL}$} & \multicolumn{2}{|l|}{$3.2 \% \mathrm{PL}$} & \multicolumn{2}{|l|}{$3.6 \% \mathrm{PL}$} & \multicolumn{2}{|l|}{$4.2 \% \mathrm{PL}$} \\
\hline & & Krill & Soy & Krill & Soy & Krill & Soy & Krill & Soy \\
\hline $14: 0$ & $3.9 \pm 0.3$ & $4.0 \pm 0.2$ & $3.1 \pm 0.1$ & $3.8 \pm 0.1$ & $4.0 \pm 0.1$ & $4.9 \pm 0.2$ & $3.5 \pm 0.2$ & $8.4 \pm 0.5$ & $2.1 \pm 0.2$ \\
\hline $16: 0$ & $15.4 \pm 1.0$ & $15.0 \pm 0.5$ & $14.8 \pm 0.2$ & $14.6 \pm 0.6$ & $18.5 \pm 0.2$ & $16.1 \pm 0.7$ & $18.6 \pm 0.5$ & $22.2 \pm 1.3$ & $20.0 \pm 1.0$ \\
\hline $18: 0$ & $3.2 \pm 0.4$ & $2.7 \pm 0.2$ & $3.0 \pm 0.2$ & $2.5 \pm 0.1$ & $3.4 \pm 0.2$ & $2.3 \pm 0.2$ & $3.4 \pm 0.1$ & $2.3 \pm 0.1$ & $3.8 \pm 0.3$ \\
\hline Total Saturates $^{1}$ & $23.6 \pm 1.7$ & $22.7 \pm 0.6$ & $21.8 \pm 0.4$ & $21.8 \pm 0.8$ & $27.0 \pm 0.3$ & $24.2 \pm 1.1$ & $26.6 \pm 0.7$ & $33.6 \pm 1.9$ & $26.9 \pm 1.3$ \\
\hline $16: 1 n-7$ & $3.9 \pm 0.3$ & $3.7 \pm 0.2$ & $3.2 \pm 0.2$ & $3.3 \pm 0.1$ & $4.2 \pm 0.1$ & $3.8 \pm 0.3$ & $3.7 \pm 0.2$ & $6.0 \pm 0.3$ & $2.1 \pm 0.3$ \\
\hline $18: 1 n-9$ & $28.2 \pm 1.6$ & $27.7 \pm 1.1$ & $29.6 \pm 2.0$ & $32.3 \pm 1.3$ & $20.3 \pm 1.3$ & $27.9 \pm 1.1$ & $18.6 \pm 1.3$ & $13.9 \pm 1.0$ & $20.0 \pm 1.4$ \\
\hline $18: 1 n-7$ & $2.9 \pm 0.1$ & $3.1 \pm 0.0$ & $2.7 \pm 0.1$ & $3.5 \pm 0.1$ & $2.7 \pm 0.1$ & $3.9 \pm 0.0$ & $2.5 \pm 0.1$ & $4.9 \pm 0.1$ & $2.2 \pm 0.1$ \\
\hline $20: 1 n-9$ & $3.3 \pm 1.0$ & $2.7 \pm 0.8$ & $2.6 \pm 0.6$ & $1.8 \pm 0.1$ & $3.1 \pm 0.7$ & $1.4 \pm 0.2$ & $2.7 \pm 0.5$ & $1.1 \pm 0.1$ & $1.0 \pm 0.1$ \\
\hline $22: 1 n-11$ & $3.9 \pm 0.9$ & $3.0 \pm 0.7$ & $3.0 \pm 0.6$ & $1.2 \pm 0.1$ & $4.0 \pm 0.9$ & $0.7 \pm 0.1$ & $3.3 \pm 0.7$ & $0.8 \pm 0.0$ & $1.0 \pm 0.1$ \\
\hline Total Monoenes $^{2}$ & $43.9 \pm 1.1$ & $41.9 \pm 0.5$ & $42.7 \pm 1.0$ & $43.2 \pm 1.3$ & $35.9 \pm 0.4$ & $38.9 \pm 1.0$ & $32.1 \pm 0.9$ & $28.2 \pm 0.9$ & $27.9 \pm 1.8$ \\
\hline $18: 2 n-6$ & $13.3 \pm 0.6$ & $13.9 \pm 0.3$ & $18.4 \pm 0.4$ & $16.2 \pm 0.5$ & $18.3 \pm 0.8$ & $14.7 \pm 0.5$ & $23.2 \pm 0.5$ & $8.7 \pm 0.7$ & $34.0 \pm 1.8$ \\
\hline $20: 4 n-6$ & $0.4 \pm 0.0$ & $0.4 \pm 0.0$ & $0.3 \pm 0.0$ & $0.3 \pm 0.0$ & $0.4 \pm 0.0$ & $0.3 \pm 0.0$ & $0.4 \pm 0.0$ & $0.4 \pm 0.0$ & $0.2 \pm 0.0$ \\
\hline Total n-6 PUFA ${ }^{3}$ & $14.2 \pm 0.6$ & $14.7 \pm 0.3$ & $19.1 \pm 0.4$ & $16.8 \pm 0.5$ & $19.2 \pm 0.8$ & $15.3 \pm 0.5$ & $24.0 \pm 0.5$ & $9.4 \pm 0.7$ & $34.5 \pm 1.8$ \\
\hline $18: 3 n-3$ & $3.4 \pm 0.3$ & $3.7 \pm 0.2$ & $3.9 \pm 0.2$ & $4.3 \pm 0.3$ & $2.7 \pm 0.0$ & $3.8 \pm 0.2$ & $2.9 \pm 0.1$ & $1.6 \pm 0.1$ & $3.5 \pm 0.2$ \\
\hline $18: 4 n-3$ & $1.2 \pm 0.2$ & $1.5 \pm 0.0$ & $1.1 \pm 0.0$ & $1.2 \pm 0.1$ & $1.3 \pm 0.0$ & $1.5 \pm 0.1$ & $1.3 \pm 0.2$ & $2.5 \pm 0.1$ & $0.6 \pm 0.3$ \\
\hline $20: 4 n-3$ & $0.4 \pm 0.1$ & $0.4 \pm 0.0$ & $0.3 \pm 0.0$ & $0.2 \pm 0.0$ & $0.4 \pm 0.0$ & $0.2 \pm 0.0$ & $0.4 \pm 0.0$ & $0.3 \pm 0.0$ & $2.6 \pm 0.3$ \\
\hline $20: 5 n-3$ & $5.1 \pm 0.7$ & $6.6 \pm 0.4$ & $4.2 \pm 0.3$ & $6.1 \pm 0.3$ & $5.2 \pm 0.3$ & $8.4 \pm 0.4$ & $4.8 \pm 0.3$ & $13.4 \pm 1.1$ & $2.6 \pm 0.3$ \\
\hline $22: 5 n-3$ & $0.8 \pm 0.2$ & $0.7 \pm 0.0$ & $0.6 \pm 0.0$ & $0.4 \pm 0.0$ & $0.7 \pm 0.1$ & $0.4 \pm 0.0$ & $0.7 \pm 0.1$ & $0.6 \pm 0.1$ & $0.3 \pm 0.0$ \\
\hline $22: 6 n-3$ & $6.5 \pm 0.9$ & $7.0 \pm 0.4$ & $5.5 \pm 0.5$ & $5.1 \pm 0.4$ & $6.5 \pm 0.5$ & $6.2 \pm 0.2$ & $6.3 \pm 0.5$ & $8.7 \pm 0.7$ & $3.7 \pm 0.5$ \\
\hline Total n-3 PUFA ${ }^{4}$ & $17.5 \pm 2.1$ & $19.8 \pm 0.7$ & $15.7 \pm 0.9$ & $17.4 \pm 1.0$ & $17.0 \pm 1.0$ & $20.6 \pm 0.7$ & $16.5 \pm 1.2$ & $27.1 \pm 2.0$ & $10.8 \pm 1.2$ \\
\hline Total PUFA ${ }^{5}$ & $32.5 \pm 2.5$ & $35.4 \pm 0.6$ & $35.4 \pm 1.3$ & $35.0 \pm 1.6$ & $37.1 \pm 0.6$ & $36.9 \pm 0.9$ & $41.3 \pm 0.9$ & $38.2 \pm 1.5$ & $45.8 \pm 2.6$ \\
\hline
\end{tabular}

Values are the averaged data for the $0.5,0.8$ and $1.1 \mathrm{~mm}$ feeds (with SD provided to illustrate variance between feeds).

PUFA, polyunsaturated fatty acids. ${ }^{1}$ Totals include $14: 0,15: 0,20: 0$ and 22:0; ${ }^{2}$ Totals include 16:1n-9, 20:1n-11, 20:1n-722:1n-9 and 24;1n-9;

${ }^{3}$ Totals include 18:3n-6, 20:2n-6, and 22:5n-6; ${ }^{4}$ Totals include 20:3n-3; ${ }^{5}$ Totals include C16

PUFA. 
2 Table 4. Mortality, SGR, TGC and FCR from first feed to smolt

\begin{tabular}{llllll}
\hline PL Level & PL Origin & Mortality $\%$ & SGR & TGC & FCR \\
\hline $1.5 \%$ & Base & $5.42 \pm 0.49$ & $1.39 \pm 0.12$ & $1.00 \pm 0.17$ & $0.79 \pm 0.13$ \\
$2.6 \%$ & Krill & $3.92 \pm 0.99$ & $1.45 \pm 0.08$ & $1.09 \pm 0.06$ & $0.78 \pm 0.08$ \\
& Soy & $4.86 \pm 0.42$ & $1.34 \pm 0.14$ & $0.92 \pm 0.13$ & $0.86 \pm 0.13$ \\
$3.2 \%$ & Krill & $4.57 \pm 1.31$ & $1.42 \pm 0.32$ & $1.03 \pm 0.27$ & $0.84 \pm 0.09$ \\
& Soy & $5.50 \pm 0.67$ & $1.41 \pm 0.16$ & $1.03 \pm 0.17$ & $0.89 \pm 0.14$ \\
$3.6 \%$ & Krill & $3.57 \pm 0.90$ & $1.39 \pm 0.22$ & $0.99 \pm 0.16$ & $0.84 \pm 0.12$ \\
& Soy & $4.22 \pm 0.42$ & $1.43 \pm 0.19$ & $1.05 \pm 0.15$ & $0.78 \pm 0.08$ \\
& Soy & $4.26 \pm 0.15$ & $1.39 \pm 0.10$ & $0.98 \pm 0.08$ & $0.76 \pm 0.09$ \\
\hline
\end{tabular}

3 4 5 6 7 8 9 10 11 12 13 14 15 16 17 18 19

*Data only until $10-15 \mathrm{~g}$ as the $4.2 \%$ krill phospholipid treatment was terminated after this point. 
Fig. 1.

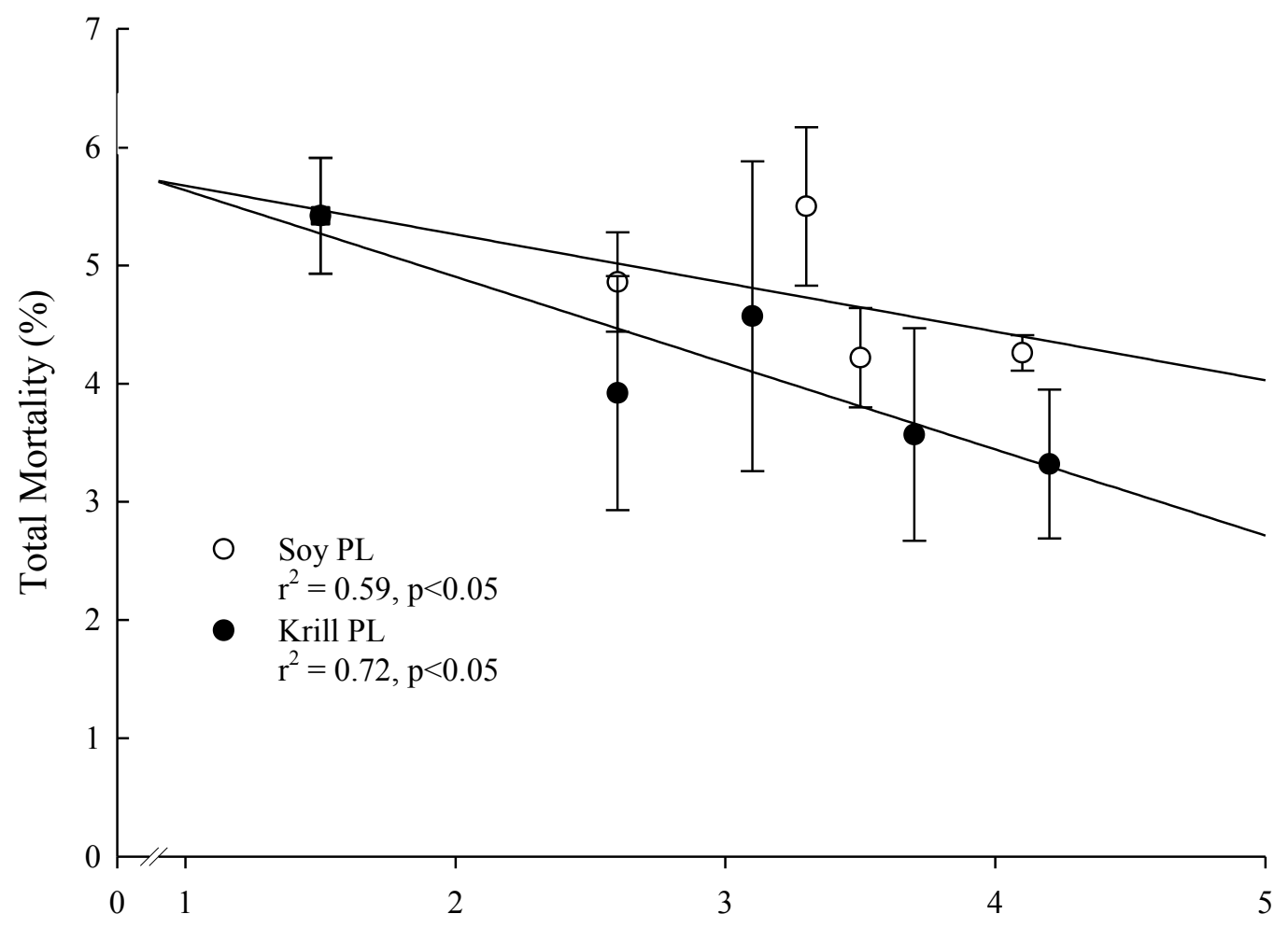


33 Fig. 2.
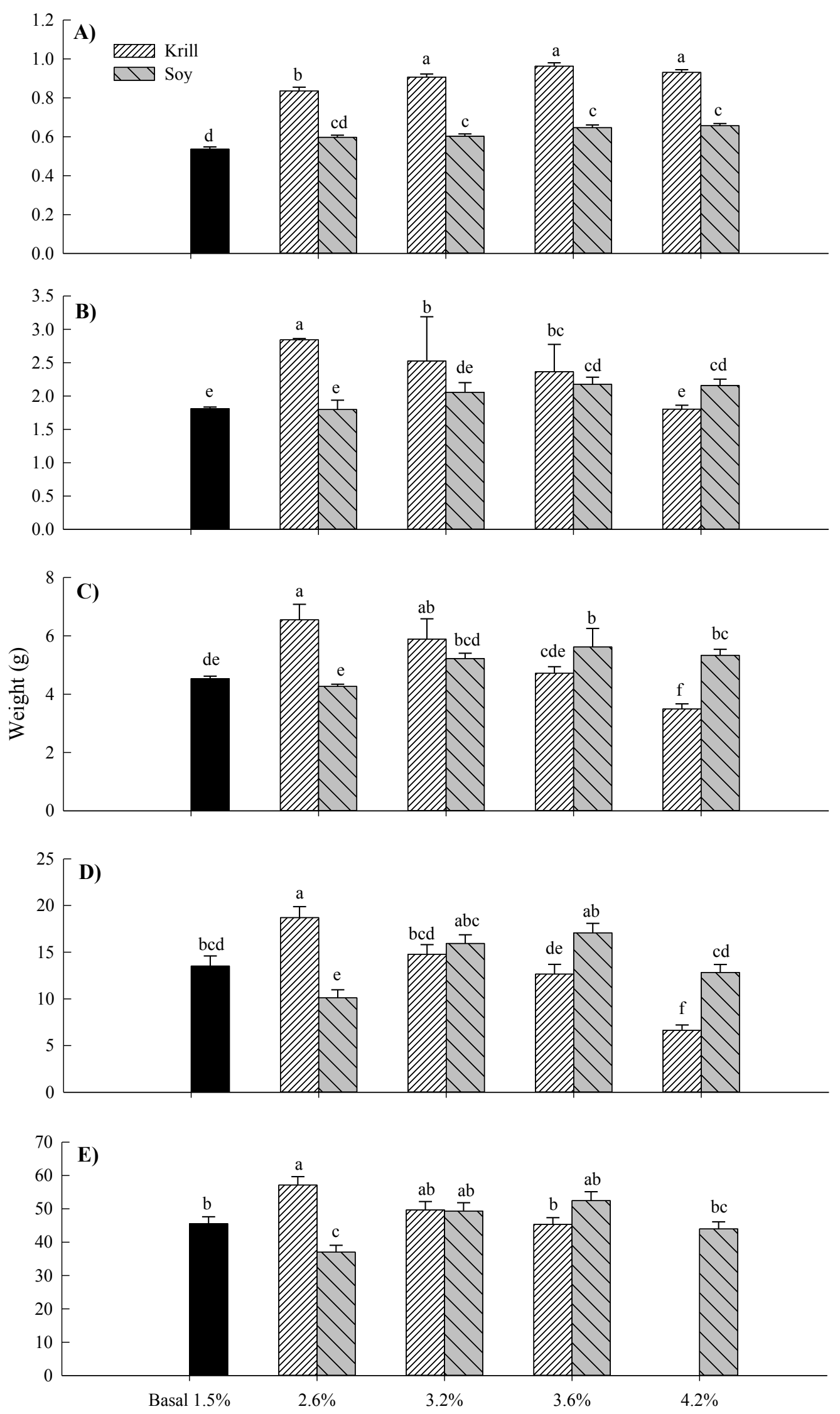

Phospholipid Level (\% Diet) 
Fig. 3.

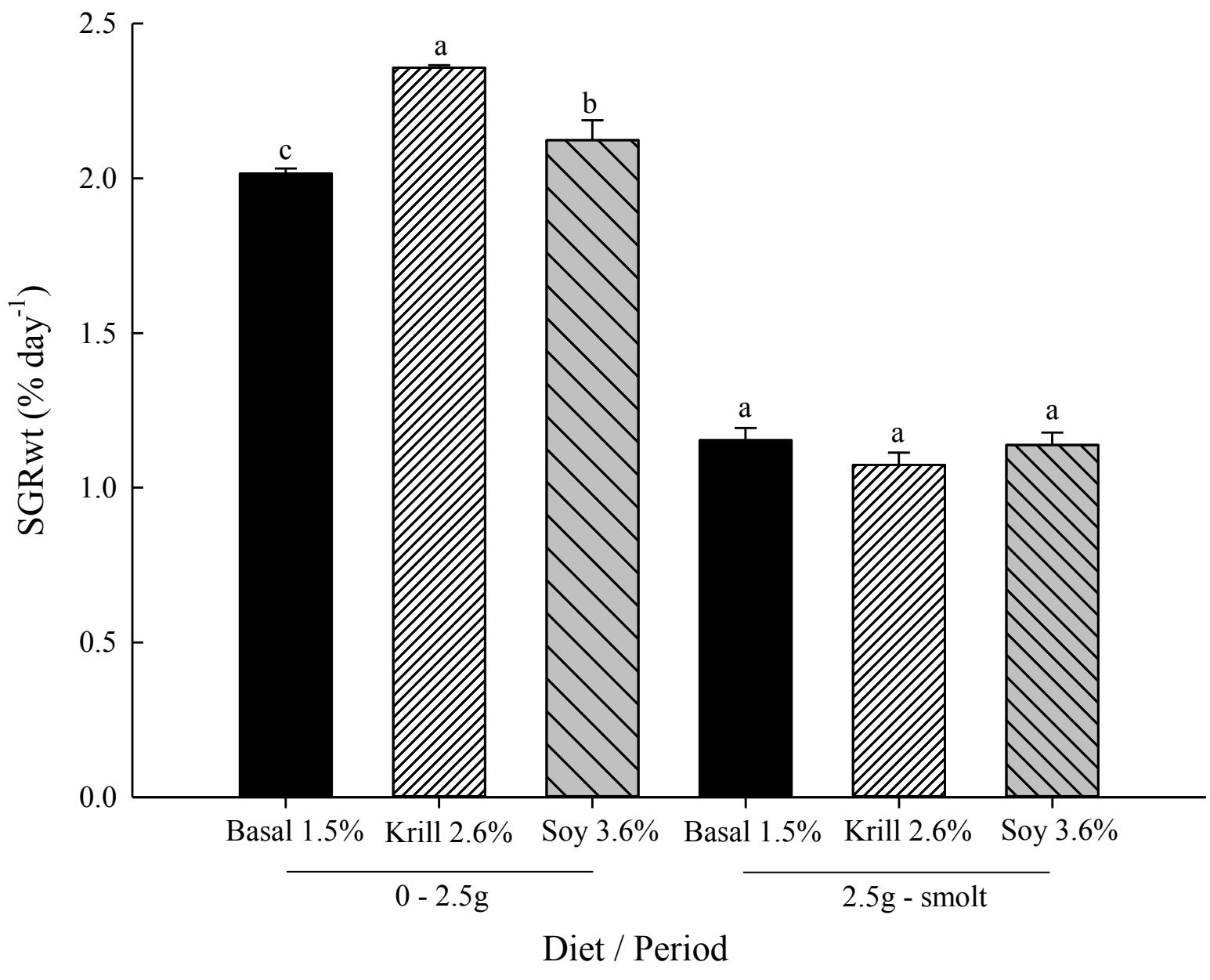


Fig. 4.

40

A)

B)
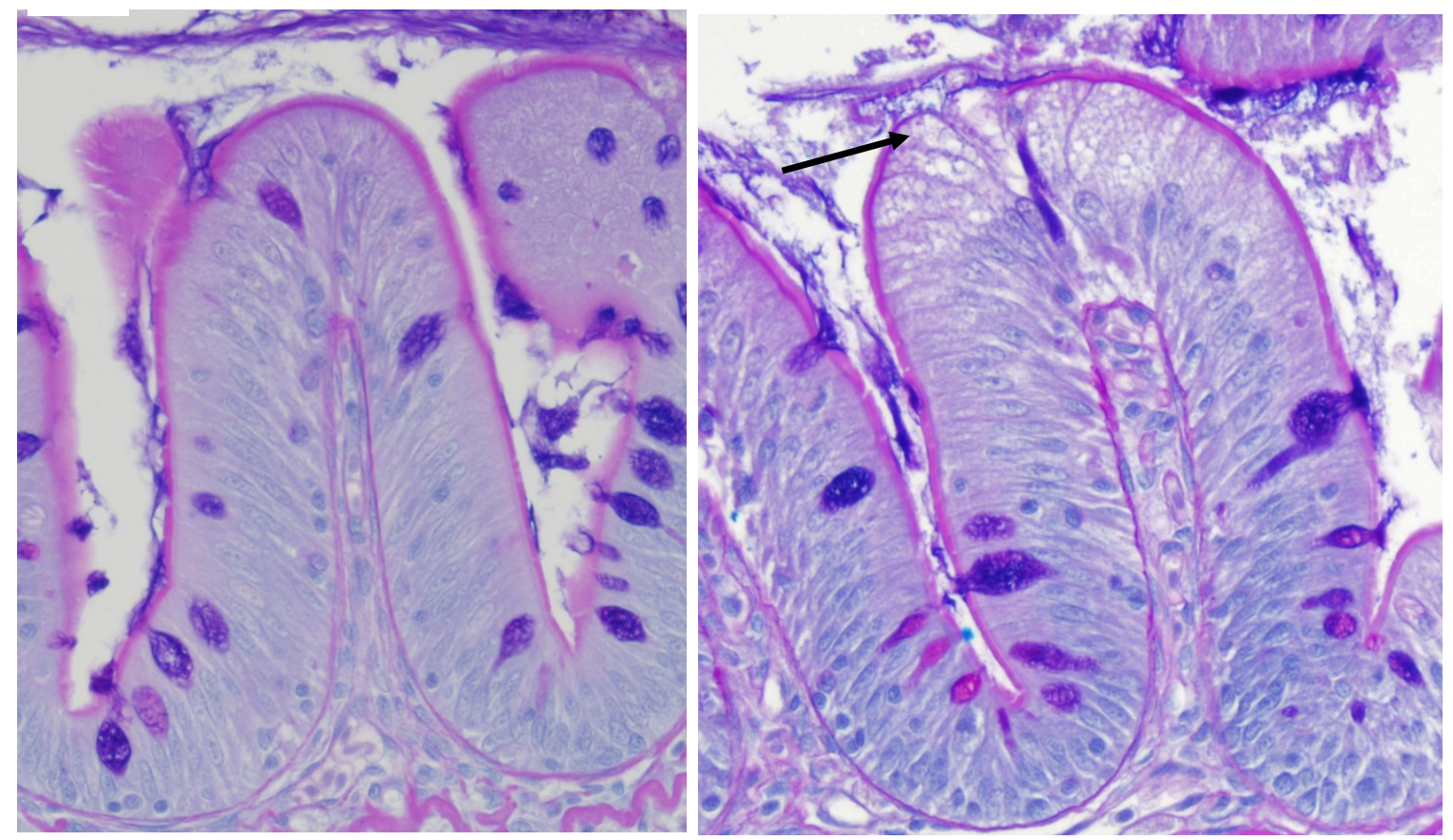

42 
Fig. 5.

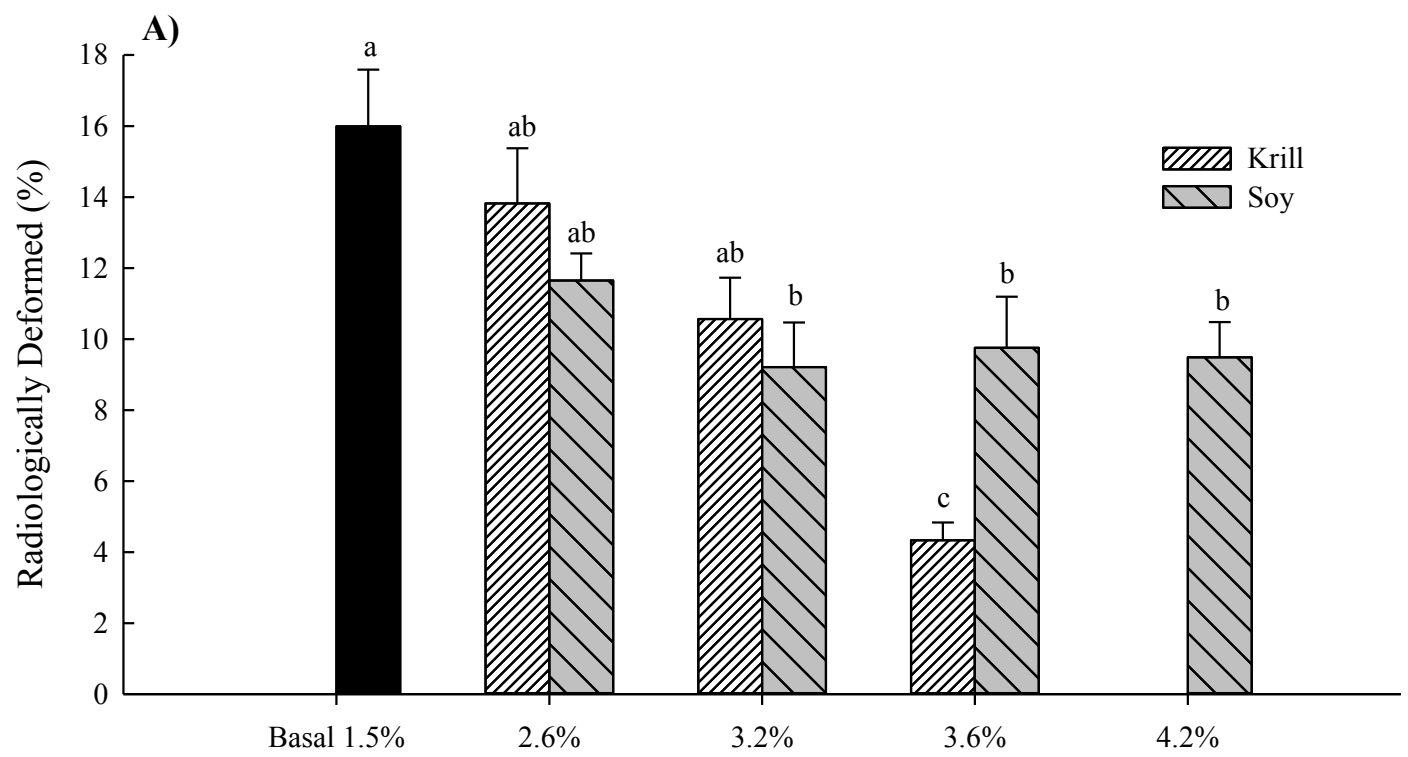

B)

Phospholipid Level (\% Diet)

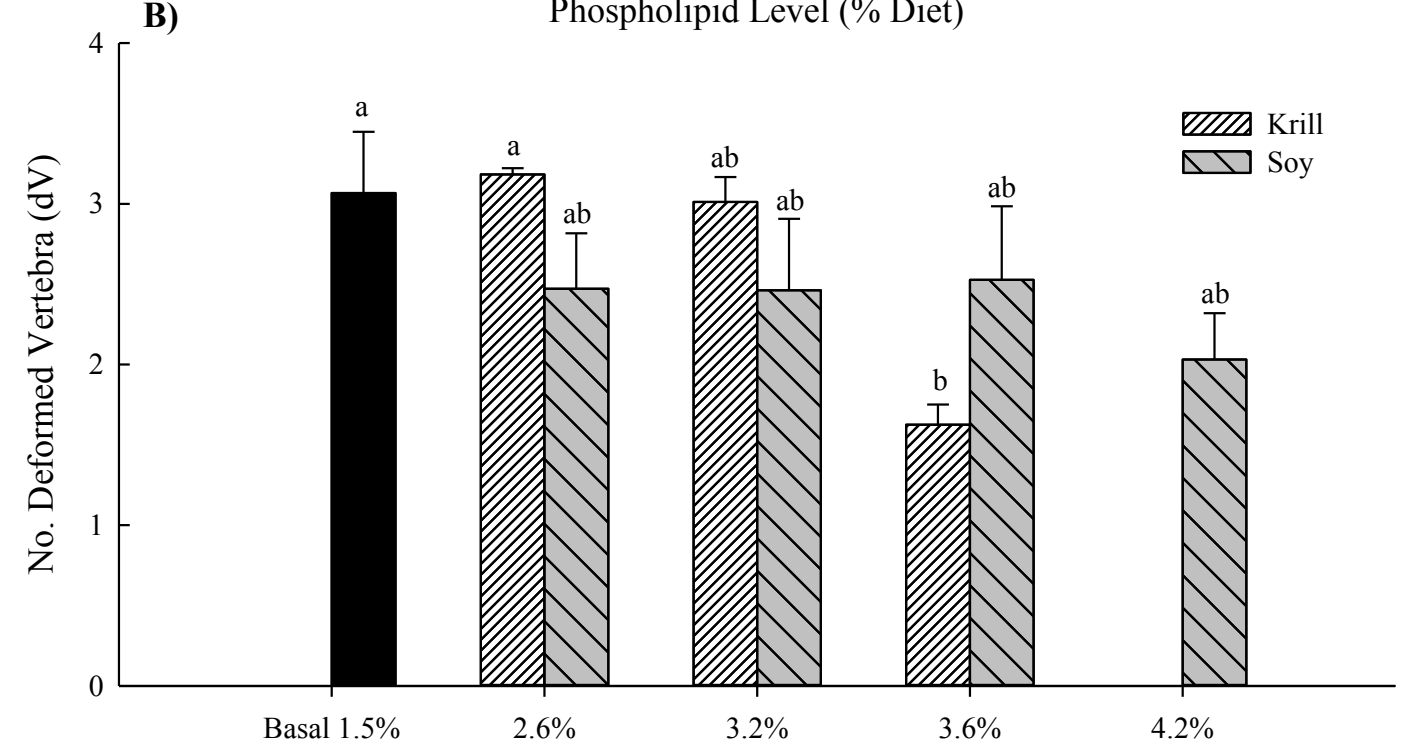

Phospholipid Level (\% Diet)

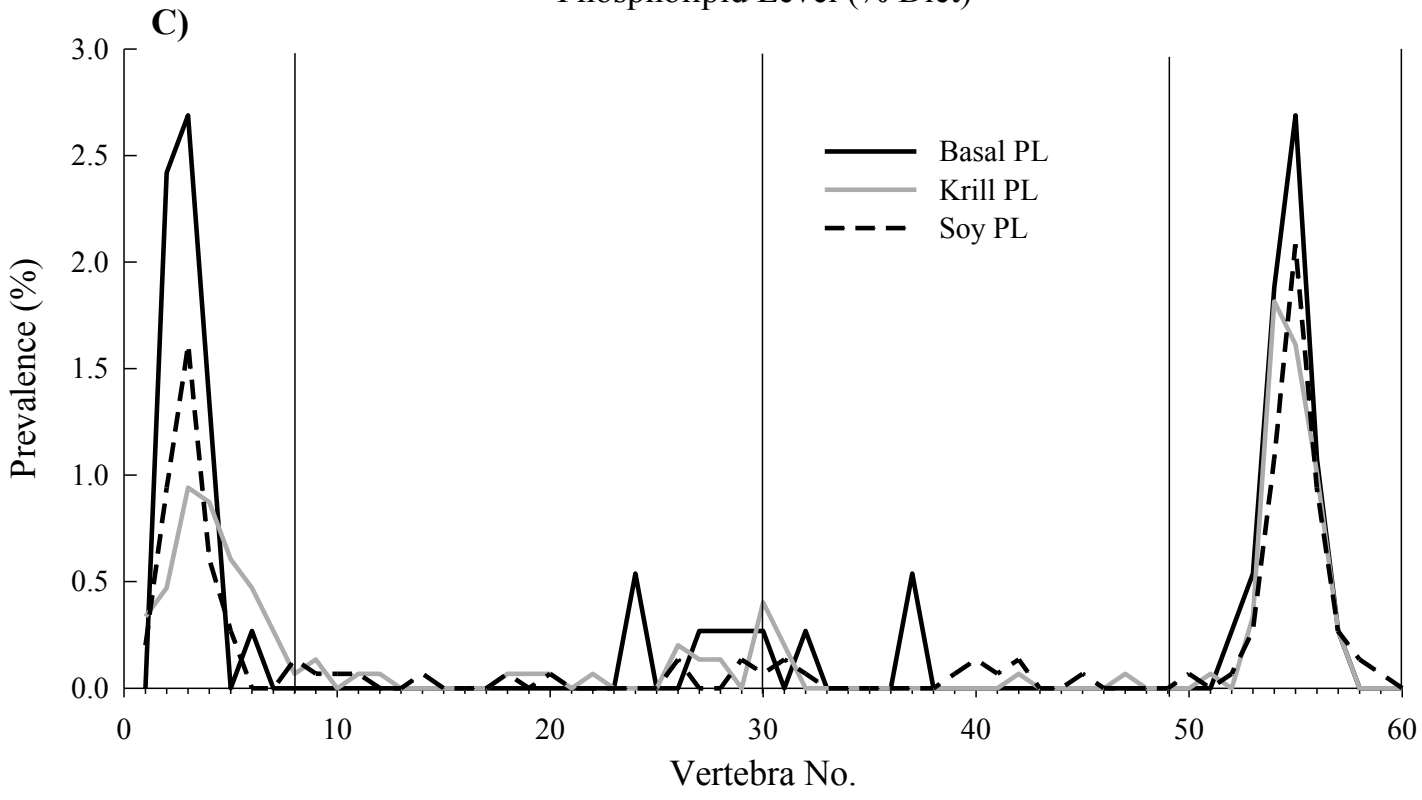


Fig. 6.

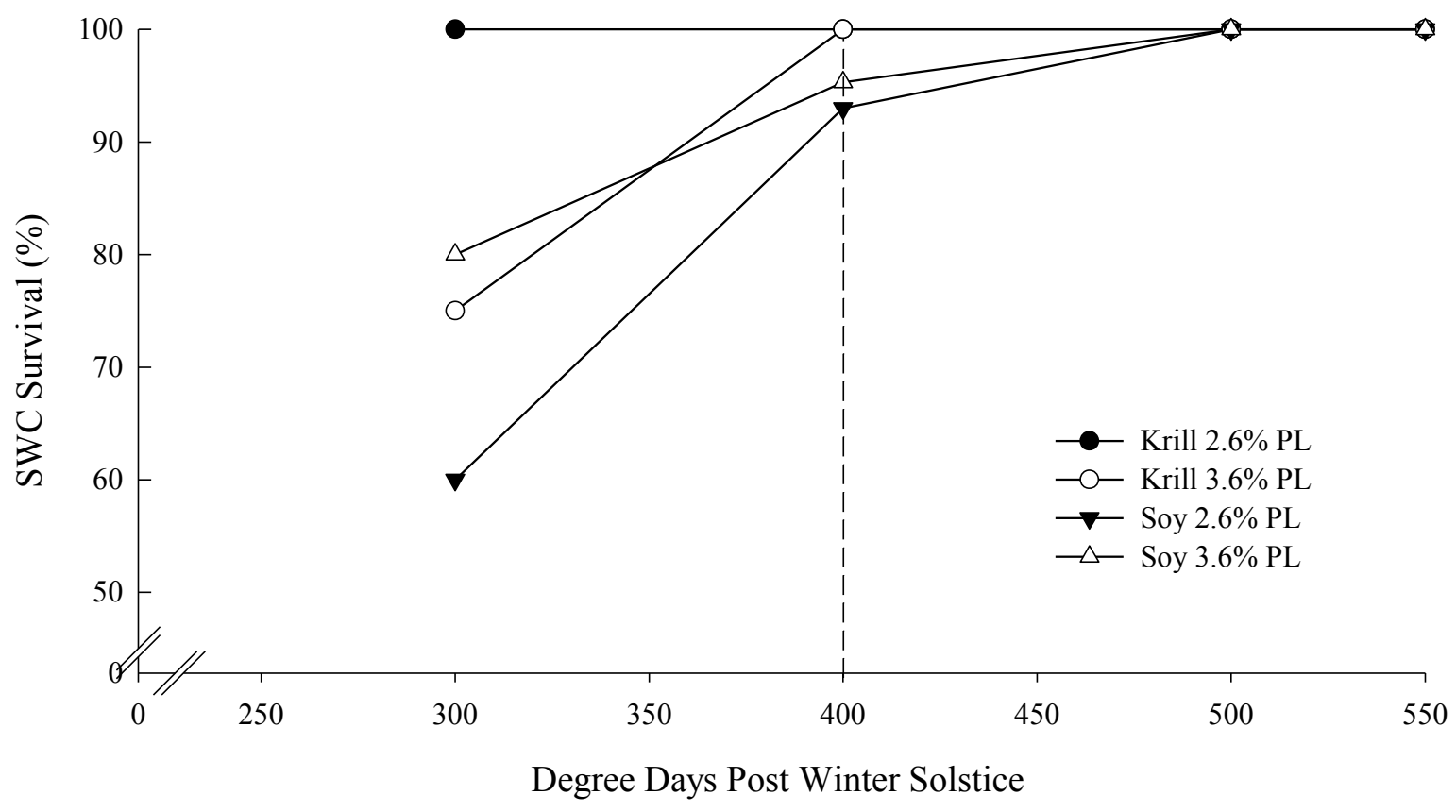

